\title{
ABSTRACTS OF THE SOUTH AFRICAN RENAL SOCIETY (SARS) 2016 CONGRESS (CAPE TOWN 9-11 SEPTEMBER 2016)
}

The following abstracts were presented as oral or poster presentations. Abstracts are published as received. Those abstracts which were accepted for presentation at the Congress but were later withdrawn by the authors have been omitted.

\section{ORAL PRESENTATION ABSTRACTS}

Adult and paediatric nephrology session, 10 September, 2016, 09:40 - 10:00

\section{Favourable prognosis with renal replacement therapy, among South African public health sector patients with end-stage renal disease and hiv-infection, and baseline cd4-cell counts between 50 and 200 cells $/ \mathrm{mm}^{3}$}

\author{
H Somaroo ${ }^{1,2}$, S Hariparshad ${ }^{3}$, AGH Assounga ${ }^{3}$, S Naicker ${ }^{4}$, O Mohamed ${ }^{1}$ \\ ${ }^{1}$ University of KwaZulu-Natal; ${ }^{2}$ Ethekwini District, Department of Health; ${ }^{3}$ Inkosi Albert Luthuli Central Hospital; \\ ${ }^{4}$ University of the Witwatersrand
}

\section{Introduction}

Improved survival among individuals with human immunodeficiency virus (HIV), in an era of increasing antiretroviral therapy (ART) coverage, produced an epidemiological transition amongst co-morbid illnesses. Increasing prevalences of chronic diseases, including End-stage Renal Disease (ESRD), prompted responsive management. The South African public health policy for renal replacement therapy (RRT) was amended in 2007, to include eligible patients with HIV-infection, though there have been limited reports on clinical outcomes among this population. We investigated outcomes following RRT, among patients with HIV-infection and ESRD, who received renal dialysis. Methods: A retrospective, observational, cohort study was conducted at a central hospital in KwaZuluNatal, South Africa. Patients with HIV-infection and ESRD, who received RRT and were considered for inclusion into the province's Chronic Dialysis Programme, were studied. Data was extracted from the hospital's electronic information system, for a seven-year period (2008-2014). Overall survival of patients, following RRT initiation, was estimated using the Kaplan-Meier method. Predictors of survival were determined using logistic regression analyses.

Results: The prevalence of HIV-infection among patients who received RRT was $11.69 \%$ (95\% CI: 10.08-13.30). Ninety-four patients were included in the study, of whom $61.70 \%(n=58)$ were female and $98.94 \%$ ( $\mathrm{n}=93$ ) were black-African. Median age was 35.1 years (IQR: 30.0-42.2 years). Co-morbid chronic conditions included hypertension $[92.5 \%(\mathrm{n}=87)]$ and diabetes mellitus [8.5\% $(\mathrm{n}=9)]$. One-year survival rate was $81.51 \%$. On multivariate analysis, lower mortality was associated with baseline CD4-cell counts between 50 and 200 cells $/ \mathrm{mm}^{3}$ [OR $=0.02$ (95\% CI: $\left.0.01-0.40\right)$ ], age $<50$ years [OR $=0.31(95 \%$ 
CI: 0.07-1.61)], and baseline ART exposure [OR=0.73(95\% CI: 0.23-2.33)]. Lower mortality with prior ART exposure was not associated with duration of ART $\geq$ six months [OR=1.07(95\% CI: 0.40-2.90)]. Conclusion and Recommendations: Patients with co-morbid HIV-infection and ESRD, who satisfy other eligibility criteria, should not be excluded from receiving RRT if ART exposure is $<$ six months or baseline CD4-cell count is between 50 and 200 cells $/ \mathrm{mm}^{3}$, as their prognosis may be more favourable than previously perceived. 


\title{
ABSTRACTS OF THE SOUTH AFRICAN RENAL SOCIETY (SARS) 2016 CONGRESS (CAPE TOWN 9-11 SEPTEMBER 2016)
}

\section{ORAL PRESENTATION ABSTRACTS}

Adult and paediatric nephrology session, 10 September, 2016, 10:00 - 10:20

\section{Gitelman syndrome in a South African family presenting with Hypokalaemia and unusual food cravings}

Pieter Du Toit van der Merwe ${ }^{1}$, Megan A. Rensburg ${ }^{2}$, William L. Haylett ${ }^{3}$, Soraya Bardien ${ }^{3}$, M. Razeen Davids ${ }^{1}$ ${ }^{1}$ Division of Nephrology, Department of Medicine, Stellenbosch University and Tygerberg Hospital, Cape Town, South Africa;

${ }^{2}$ Division of Chemical Pathology, Stellenbosch University and National Health Laboratory Service, Cape Town, South Africa; ${ }^{3}$ Division of Molecular Biology and Human Genetics, Stellenbosch University, Cape Town, South Africa

\begin{abstract}
Background: Gitelman Syndrome (GS) is an autosomal recessive renal tubular disorder characterised by renal salt wasting with hypokalaemia, metabolic alkalosis, hypomagnesaemia and hypocalciuria. It is caused by mutations in SLC12A3 encoding the sodium-chloride co-transporter on the apical membrane of the distal convoluted tubule. We report on a South African family with five affected individuals presenting with hypokalaemia and unusual food cravings.

Methods: The affected individuals and two unaffected first degree relatives were enrolled into the study. Phenotypes were evaluated through history, physical examination and biochemical analysis of blood and urine. Mutation screening was performed by the sequencing of SLC12A3, and determining the allele frequencies of the sequence variants found in this family in 117 ethnically matched controls. Results: The index patient, her sister, father and two aunts had a history of severe salt cravings, fatigue and tetanic episodes, leading to consumption of large quantities of salt and vinegar. All affected individuals demonstrated hypokalaemia with renal potassium wasting. Genetic analysis revealed that the pseudo-dominant pattern of inheritance was due to compound heterozygosity with two novel mutations: a S546G substitution in exon 13, and insertion of AGCCCC at c.1930 in exon 16. These variants were present in the five affected individuals, but only one variant each in the unaffected family members. Neither variant was found in any of the controls.

Conclusion: The diagnosis of GS was established in five members of a South African family through clinical assessment, biochemical analysis and mutation screening of the SLC12A3 gene, which identified two novel putative pathogenic mutations.
\end{abstract}

Key words: South Africa, Gitelman Syndrome, hypokalaemia, tubular disorders, salt craving, mutation, pseudo-dominant inheritance. 


\title{
ABSTRACTS OF THE SOUTH AFRICAN RENAL SOCIETY (SARS) 2016 CONGRESS (CAPE TOWN 9-11 SEPTEMBER 2016)
}

\section{ORAL PRESENTATION ABSTRACTS}

\author{
RCSSA session,10 September, 2016, 09:40 - 10:00
}

\section{The kidney-gut diet connection}

Cecile Verseput RD (SA)

\begin{abstract}
Background: There is increasing clinical evidence that patients with chronic kidney disease (CKD) have distinctly dysbiotic gut microbiota, which in turn drives a cascade of metabolic abnormalities, including excessive uremic toxin production, inflammation, and immune suppression, that ultimately promote progressive kidney failure and cardiovascular disease.

Methods: Causes of gut dysbiosis can be attributed to restricted nutrient intake from the renal diet favouring proteolytic fermentation with reduced saccharolytic production of favourable short chain fatty acids (SCFA's) from carbohydrates. This results in excessive uremic toxin production where p-cresol sulfate (PCS), indoxyl sulfate (IS) and TMAO are difficult to remove by dialysis. Urea derived ammonia impairs and disrupts the intestinal gut barrier structure causing translocation of bacteria, uremic toxins and endotoxin into the circulation.

Results: As the gut microbiota is intimately influenced by diet, the discovery of the kidney-gut axis has created new therapeutic opportunities for nutritional intervention. The gut microbiota is not only highly dependent on diet, but its plasticity makes it an attractive therapeutic target for dietary manipulation.

Dietary interventions to rectify gut dysbiosis: Dietary fibre benefits the enhanced integrity of the gastrointestinal wall and reduces levels of uremic toxins like IS, PCS and TMAO while favouring SCFA's formation. Dietary fibre supplies anti-oxidants and lowers dietary acid load. Increase dietary fibre to $10-20 \mathrm{~g} /$ day by adding cruciferous vegetables, legumes containing low bio-available phosphate, and fermentable starches such as oats and potatoes to the diet. Plant protein like legumes and tofu should replace some animal protein, specifically red meat. Resveratrol from berries, peanuts and virgin olive oil attenuates atherosclerosis by promoting favourable gut microbiota preventing formation of TMAO, known to cause cardiovascular disease and kidney disease progression. Fibre, pre- and probiotics could minimise deleterious effects of the imbalance in microbiota.
\end{abstract}

Conclusion: For gut microbiota dysbiosis reversal, adapt the principles of the anti-inflammatory Mediterranean diet. 


\title{
ABSTRACTS OF THE SOUTH AFRICAN RENAL SOCIETY (SARS) 2016 CONGRESS (CAPE TOWN 9-11 SEPTEMBER 2016)
}

\section{ORAL PRESENTATION ABSTRACTS}

RCSSA session, 10 September, 2016, 10:00 - 10:20

\section{When does Iron Overload become a Clinical Problem: A Study of Potential Predictive Indicators}

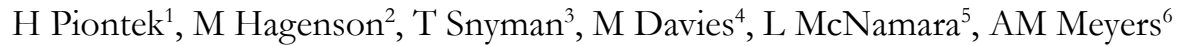 \\ ${ }^{1}$ Graduate Clinical technologist, NRC; ${ }^{2}$ Radiologist WDGMC; ${ }^{3}$ Scientist, NHLS; ${ }^{4}$ Nephrologist, Charlotte Maxeke Hospital; \\ ${ }^{5}$ Senior Researcher, Internal Medicine, University of the Witwatersrand Medical School; ${ }^{6}$ Professor (Emeritus), Internal \\ Medicine, University of the Witwatersrand Medical School
}

\begin{abstract}
Background: Anaemia management in CKD patients requires treatment of functional iron deficiency $(\mathrm{FeD})$ with intravenous iron and erythropoietin ( $\mathrm{rHuEpo}$ ) administration in order to maintain optimal haemoglobin levels. Guidelines are clear on when to initiate iron replacement, but, other than a maximum cut off level for ferritin $(500 \mathrm{ng} / \mathrm{ml})$ as defined by KDIGO and KDOQI, no specific guidelines suggest when to cease iron replacement in order to prevent overload in these patients.

In 2004 literature was published whereby liver iron was calculated in CKD patients using a very expensive superconducting quantum interference device (SQUID). In validating these calculations with ferritin (FRT) the conclusion suggested that $>340 \mu \mathrm{g} / \mathrm{l}$ represents iron overload. In the interim, several other authors identified magnetic susceptometry (MRI) as a more affordable and non-invasive method of determining iron overload.

Methods: In this study a cohort of $25 \mathrm{CKD}$ patients were selected wherein liver iron content was calculated by using MRI. Hepcidin and FRT levels were measured. Results were correlated in order to determine a value indicating iron overload.

Results: Highly significant correlation was shown between Hepcidin and liver iron content $(\mathrm{P}<0.02)$. Linear regression predicted statistically suggestive but non-significant correlation $(\mathrm{P}<0.1)$ which indicates a type II statistical error. Future studies using more subjects will be more conclusive.
\end{abstract}

Conclusion: Liver iron content of $>107.10 \mu \mathrm{mo} / \mathrm{g}$ and Hepcidin levels have shown to be valuable indicators of identifying the threshold of iron overload. 


\title{
ABSTRACTS OF THE SOUTH AFRICAN RENAL SOCIETY (SARS) 2016 CONGRESS (CAPE TOWN 9-11 SEPTEMBER 2016)
}

\section{ORAL PRESENTATION ABSTRACTS}

Adult and paediatric nephrology session, 10 September, 2016, 12:30 - 12:45

\section{Patient Outcomes in a Peritoneal Dialysis First Programme in Cape Town, South Africa}

\author{
B Davidson, K Manning, N Wearne \\ Groote Schuur Hospital, University of Cape Town
}

\begin{abstract}
Background: South Africa (SA) currently does the most peritoneal dialysis (PD) in sub-Saharan Africa. Yet, outcome data is limited. With the collision of epidemics of communicable and non-communicable diseases in Africa, the need for cost effective dialysis is escalating. PD remains a life-saving modality especially as access to hemodialysis is limited in many settings.

Methods: We retrospectively analysed all patients undergoing PD at Groote Schuur Hospital from January 2008 until June 2014, and thereafter prospectively until June 2015. Variables included demographics (age, sex and race), adequacy measures, fluid status, PD fluid, cardiovascular risk profile and diabetes. The influence of these variables on peritonitis rate, catheter malfunction, technique and patient survival were assessed.

Results: A total of 230 patients were initiated on PD, 31 were excluded as they were on PD for $<90$ days. The mean age was 39.7+/-10.4 years (SD), 49.8\% were male and $63.8 \%$ were mixed ancestry. Hypertension $(33 \%)$ was the most common causes of end-stage renal disease. Average time on PD was 17 months (IQR 8-32). The peritonitis rate was 0.87 events per patient years. One, two and five-year patient and technique survival was $94.4 \%, 84.3 \%$ and $60.2 \%$ and $84.6 \%, 75.7 \%$ and $45.9 \%$ respectively. Diabetes (HR 2.74, 95\% CI 1.02-7.35; $\mathrm{p}=0.045)$, failure to reach targeted haemoglobin of $<20$ (HR 2.06, CI 1.31-3.25; $\mathrm{p}=0.002$ ) and fluid overload (HR 1.90, CI 1.19-3.04; $\mathrm{p}=0.007$ ) were significant predictors of patient survival. The African race $(p=0.016)$ and failure to reach haemoglobin target $(p=0.005)$ were both predictors of technique failure.
\end{abstract}

Conclusion: In our PD first programme the results were encouraging, despite the lack of home visits due to safety, resource limitations and a high disease burden. Technique failure in the African race needs further evaluation. However, we truly believe that peritoneal dialysis is a viable, life-saving modality in an African setting. 


\title{
ABSTRACTS OF THE SOUTH AFRICAN RENAL SOCIETY (SARS) 2016 CONGRESS (CAPE TOWN 9-11 SEPTEMBER 2016)
}

\section{ORAL PRESENTATION ABSTRACTS}

Adult and paediatric nephrology session, 10 September, 2016, $12: 45$ - 13:00

\section{The Impact of Vascular Calcification among Dialysis Dependent South African CKD Patients. A Five-year follow- up study. Cardiovascular Mortality and Morbidity, Ethnic Variation and Hemodynamic Correlates}

\author{
K Simba, BL Rayner, M Borkum, R Freercks
}

\begin{abstract}
Background: Cardiovascular disease is prevalent in CKD patients attributed mainly to vascular calcification. Studies in Western countries suggest a survival advantage among blacks on dialysis, however there is little data on this in sub-Saharan Africa.

Methods: A five-year follow-up study of dialysis patients recruited to assess vascular calcification. Participants were recalled for the following: anthropometry, vascular stiffness measurement using a Sphygmocor device and an electrocardiogram (ECG). Medical records were reviewed.

Results: Of the 66 participants - 12 of 34 (36.4\%) blacks had died, as well as 12 of 32 (37.5\%) nonblacks ( $\mathrm{p}=0.686)$; 11 of $37(30 \%)$ patients with coronary artery calcium (CAC) score $\geq 1$ died versus 13 of $29(45 \%)$ with CAC score of $0(\mathrm{p}=0.147) ; 2$ of 37 with CAC score of 0 had a parathyroidectomy compared to 7 of 29 with CAC score $\geq 1$ ( $\mathrm{p}=0.036$ ). Central aortic systolic pressure (CASP) at baseline and after five years was $134.0 \pm 25.81 \mathrm{mmHg}$ versus $133.6 \pm 22.25 \mathrm{mmHg}(\mathrm{p}=0.592)$. Alive participants with a CAC score of 0 had a CASP of $131.6 \pm 20.82 \mathrm{mmHg}$ versus $136 \pm 24.88 \mathrm{mmHg}(\mathrm{p}=0.491)$ in those with CAC score $\geq 1$. Pulse pressure at baseline and after five years was $53.5 \pm 41.5-62.0 \mathrm{mmHg}$ versus $38 \pm 33.0-52.0 \mathrm{mmHg}(\mathrm{p}<0.001)$. Augmentation index was $82(70-92.5)$ at baseline and 24(14.0-31.0) at five years $(\mathrm{p}<0.0001)$. Subjects with a baseline CAC score of 0 had a PVW of $7.8 \pm 2.19$ versus $7.8 \pm 1.33$ in those with CAC score $\geq 1$ ( $\mathrm{p}=0.983$ ). Left ventricular hypertrophy (LVH) by Cornell score was 2,208 $(1,584-2,976)$ at baseline versus $1,474(1,064-1,936)$ at five years $(\mathrm{p}=0.005)$. Those alive at follow-up had a higher BMI $28.0 \pm 5.69 \mathrm{~kg} / \mathrm{m}^{2}$ versus baseline $23.7 \pm 4.31 \mathrm{~kg} / \mathrm{m}^{2}(\mathrm{p}<0.0001)$, while 8 of $35(23 \%)$ transplanted developed diabetes $(\mathrm{p}=0.028)$.
\end{abstract}

Conclusion: There was an unexplained dissociation between CAC and vascular stiffness parameters. A regression in LVH on ECG was not explained by improved CASP. Previous parathyroidectomy was significantly associated with CAC. BMI significantly increased at follow-up as well as diabetes incidence in transplant patients. 


\title{
ABSTRACTS OF THE SOUTH AFRICAN RENAL SOCIETY (SARS) 2016 CONGRESS (CAPE TOWN 9-11 SEPTEMBER 2016)
}

\section{ORAL PRESENTATION ABSTRACTS}

RCSSA: Hemodialysis session, 10 September, 2016, 11:30 - 11:50

\section{The Evaluation of the Morse Fall Scale in patients undergoing Chronic Hemodialysis}

\author{
Dipika Ramnarayan \\ Durban University of Technology, National Renal Care
}

\begin{abstract}
Introduction: The risk of falling in patients undergoing chronic hemodialysis (CHD) is high due to factors affecting their gait and stability. The dialysis patient population is also made up of an elderly group, especially in the private sector. The study used the Morse Fall Scale (MFS) as a fall assessment tool to evaluate how susceptible a patient on CHD is to falling.

Methods: This research study used a prospective, qualitative approach. It was based on 40 patients in uMhlanga who were undergoing CHD. Each patient selected to be part of the study was given a letter of information explaining the purpose of the study, and a letter of consent which they signed. The participants completed a Morse Fall Survey, and data was then analysed by a statistician.

Results: The Morse Fall Scale was analysed using age and gender as the two main variables. Of the total number of patients selected for this study as per classification, $30 \%$ were elderly patients ( $x \geq 60$ years), $55 \%$ were middle aged patients $(30 \leq \mathrm{x}<60$ years), and $15 \%$ were young patients $(10 \leq \mathrm{x}<30)$. Elderly patients had the largest number of high risk participants, with young patients having the least. Of the 22 males, $17(42.5 \%)$ were scored as low risk, $4(10 \%)$ were scored as moderate risk, and $1(2.5 \%)$ was scored as high risk, while of the 18 female patients, 7 (17.5\%) were scored as low risk, 7 (17.5\%) were scored as moderate risk, and $4(10 \%)$ were scored as high risk patients. Data revealed $80 \%$ of the patients classified as high risk were females, and $20 \%$ were males.
\end{abstract}

Conclusion: As expected, elderly people are at the highest risk for falls and females seem to be at great risk. Limitations of this study include the small numbers which may create a bias. Future studies should take this limitation into account and explore why women appear to be at higher risk. 


\title{
ABSTRACTS OF THE SOUTH AFRICAN RENAL SOCIETY (SARS) 2016 CONGRESS (CAPE TOWN 9-11 SEPTEMBER 2016)
}

\section{ORAL PRESENTATION ABSTRACTS}

RCSSA: Hemodialysis session, 10 September, 2016, 11:50 - 12:15

\section{The Lived Experiences of Patients Dialysing in Isolation on a Hemodialysis Programme}

\author{
T Govender \\ National Renal Care, South Africa
}

\begin{abstract}
Introduction: Hemodialysis patients who are infected with multi-resistant organisms (MROs) are isolated during dialysis. This is done to prevent spread of infection. The aim of this study was to understand the lived experiences of patients being dialysed in isolation at the National Renal Care in KwaZulu-Natal.

Methods: A phenomenological research design that was qualitative, explorative and contextual in nature was utilised and conducted in six hemodialysis units in KwaZulu-Natal. The data collection methods utilised was phenomenological interviews, naïve sketches and field notes. Purposive sampling guided by data saturation, was used with nine participants dialysing in isolation for more than three months.

Results: The findings revealed that the participants' experiences of being dialysed in isolation reflected in the following identified themes, namely, loss of identity and control; low self-esteem and self-worth; feeling that they were "dirty and unclean"; unhappiness that becomes painful, stressful and fearful about infection and the effects thereof. They experienced a breakdown in relationships due to a lack of communication resulting in further loneliness. The participants had a lack of understanding and knowledge of isolation and what it meant to carry an MRO.

Based on the findings and a literature review, recommendations were proposed. The recommendations then served as a frame of reference to enable the professional nurse practitioner to render holistic nursing care to the patients dialysing in isolation.
\end{abstract}

Conclusion: It became evident that the patients who were dialysed in isolation endured multiple losses in the psychological and social dimensions. It was thus found that the phenomenon of isolation negatively impacted on the patients' health. 


\title{
ABSTRACTS OF THE SOUTH AFRICAN RENAL SOCIETY (SARS) 2016 CONGRESS (CAPE TOWN 9-11 SEPTEMBER 2016)
}

\section{ORAL PRESENTATION ABSTRACTS}

RCSSA: Hemodialysis session, 10 September, 2016, 12:15 - 12:40

\section{Prune Belly Syndrome: A 30-year experience at the Chris Hani Baragwanath Academic Hospital, South Africa}

\author{
Dr Shannon Leahy ${ }^{1}$, Dr Karen Petersen ${ }^{2}$, Prof Udai Kala ${ }^{2}$ \\ ${ }^{1}$ Department of Paediatrics (registrar), University of the Witwatersrand $;^{2}$ Department of Paediatric Nephrology, Department of \\ Paediatrics, University of the Witwatersrand
}

\begin{abstract}
Background: Prune Belly Syndrome (PBS) is a rare congenital disorder with a triad of signs: absent abdominal wall musculature, urinary tract malformations, and cryptorchidism. The complete syndrome is seen in males. Medical and surgical management aims to prevent deterioration in renal function and restore the anatomy for medical and cosmetic reasons.

Objectives: To describe the patient profile, management, hospitalisation and outcome of patients attending the Paediatric Nephrology Clinic at Chris Hani Baragwanath Academic Hospital.

Methods: Retrospective descriptive record review of patients with PBS from January 1984 to December 2014 with respect to age of presentation, associated congenital abnormalities, ultrasound findings, medical and surgical management and follow-up.

Results: Files of 44 patients were analysed. Median duration of follow-up: 24 months (1.7 months-130 months). Median age at presentation was 5.5 days (1 day-730 days). Associated conditions included: urological 50\%; orthopaedic 11\%; congenital heart disease 7\%, gastrointestinal $4.5 \%$. Sonar findings: $59 \%$ had hydronephrosis, while $43 \%$ had hydroureter. Medical management comprised of UTI prophylactic antibiotics and intermittent bladder catheterisation. Surgical management included abdominoplasty with orchidopexy (median age 3 years) and circumcision (median age 7.7 years). The median UTI/year was 1 per patient, with 52\% requiring in-hospital treatment. There was an improvement of cGFR for patients less than 2 years of age, while $56 \%$ of patients over 2 years of age were in CKD1 at the last clinic visit. Default rate was $57 \%$, active patients $25 \%, 14 \%$ of patients were transferred to an adult clinic, and $4 \%$ of patients demised.
\end{abstract}

Conclusion: Patient profile and management is comparable to other reported series. There are differences in frequencies of associated conditions. Deterioration in renal function to ESRD was observed less in this review. The high default rate needs further investigation. 


\title{
ABSTRACTS OF THE SOUTH AFRICAN RENAL SOCIETY (SARS) 2016 CONGRESS (CAPE TOWN 9-11 SEPTEMBER 2016)
}

\section{ORAL PRESENTATION ABSTRACTS}

Adult and paediatric nephrology session, 10 September, 2016, 15:45 - 16:00

\section{Vitamin D status in children with moderate to severe chronic kidney disease at the Red Cross Children's hospital, Cape Town, South Africa}

\author{
AU Solarin ${ }^{1}$, P Gajjar $^{2}$, P Nourse ${ }^{2}$ \\ ${ }^{1}$ Lagos State University Teaching Hospital, IIkeja, Lagos State, Nigeria (IPNA/ISN fellow); ${ }^{2}$ Red Cross War Memorial \\ Children's Hospital
}

\begin{abstract}
Background: Suboptimal vitamin D is quite common in the general population and relatively more common in patients with chronic kidney disease (CKD).

Objective: To determine the prevalence of vitamin D deficiency among children at Red Cross Hospital in CKD 3-5 and to identify any clinical correlates associated with vitamin D status.

Methods: The clinical records of all children less than 18 years old in CKD 3-5D attending the renal clinic at the Red Cross Children's Hospital over a one-year period were reviewed. Vitamin D levels as well as relevant clinical information was collected.

Results: The prevalence of suboptimal vitamin D levels was $73.9 \%$ (deficiency 43.5\%; insufficiency $30.4 \%)$. The degree of insufficiency was higher in older children (10 years and above) $(\mathrm{p}=0.035)$. There was no significant sex effect ( $\mathrm{p}=0.693)$, and 12 out of 15 blacks $(80 \%), 19$ of the 26 Coloureds $(73.1 \%)$, 2 of $4(50 \%)$ whites and the 1 Asian (100\%) patient had suboptimal vitamin D levels. 90\% of CKD patients had suboptimal vitamin D levels (80\% of them on peritoneal dialysis). Age, weight, height and albumin were significantly associated with vitamin D level. There was a positive linear relationship between vitamin $\mathrm{D}$ and albumin $(\mathrm{p}=0.007) .87 .5 \%$ of nephrotic patients had subnormal vitamin $\mathrm{D}$, and $80 \%$ of them were vitamin $\mathrm{D}$ deficient $(\mathrm{p}=0.04)$. Vitamin $\mathrm{D}$ deficiency/insufficiency was more common in winter, however this was not significant $(\mathrm{p}=0.387)$.
\end{abstract}

Conclusion: Suboptimal vitamin D levels is high among children with moderate to severe CKD, and significantly higher in those undergoing chronic dialysis. There is need to actively correct and monitor them in view of the emerging evidence of the role of vitamin $\mathrm{D}$ in slowing progression of CKD. 


\title{
ABSTRACTS OF THE SOUTH AFRICAN RENAL SOCIETY (SARS) 2016 CONGRESS (CAPE TOWN 9-11 SEPTEMBER 2016)
}

\section{ORAL PRESENTATION ABSTRACTS}

Adult and paediatric nephrology session, 11 September, 2016, 09:00 - 09:15

\section{The Clinical Relevance of Repeat Renal Biopsies in the Management of Lupus Nephritis: The Tygerberg Hospital Experience}

\author{
EK Tannor ${ }^{1}$, WD Bates ${ }^{2}$, MR Moosa ${ }^{1}$ \\ ${ }^{1}$ Department of Medicine, Division of Nephrology, Stellenbosch University and Tygerberg Academic Hospital, Cape Town; \\ ${ }^{2}$ Department of Anatomical Pathology, Stellenbosch University and Tygerberg Academic Hospital and National Health \\ Laboratory Service (NHLS)
}

\begin{abstract}
Background: Lupus nephritis (LN) is a complication of systemic lupus erythromatosis (SLE) with significant morbidity and mortality. SLE disease flares occur even after successful treatment. Repeat renal biopsies have been performed to identify changes in LN morphology, plan treatment and prognosticate. The clinical value of repeat renal biopsy during SLE renal flares is yet to be ascertained.

Methods: A retrospective descriptive study was conducted on repeat kidney biopsies performed between January 1984 and December 2015 in LN patients. Protocol, prognostic and disease flare biopsies were compared in a sub-analysis.

Results: Of 614 SLE renal biopsies, 127 (20.7\%) repeat biopsies were identified for analysis. Lupus disease flares accounted for $65.4 \%$ of repeat biopsies, protocol $24.4 \%$, and $10.2 \%$ for prognosis. Median interval to repeat biopsy was 24.2 months (IQR 7.8-53.1). Class IV LN was the commonest class for repeat biopsies $82(64.6 \%)$. There were no Class I LN or Class VI LN on either reference or repeat biopsy. Class was maintained in $87(68.5 \%)$ and proliferative histology was maintained in $107(85 \%)$ of the cases. Treatment did not change in 87 (69.1\%) of the cases after repeat biopsy. Cyclophosphamide was used in the treatment of both reference 90 (71.4\%) and repeat biopsies 93 (74.4\%). Mycophenolate mofetil was used in $16(12.8 \%)$ following repeat biopsies. Prednisolone alone $9(7.2 \%)$ and azathioprine $6(4.8 \%)$ were less frequently used after repeat biopsies.

Response to immunosuppression after repeat biopsy was poor: $63(52.9 \%)$ failed to respond in six months and $21(17.7 \%)$ achieved complete remission. Non-response was associated with low serum albumin $(\mathrm{OR}=0.87, \mathrm{P}=0.041)$ and high chronicity index $(\mathrm{OR}=1.6, \mathrm{P}=0.026) . \mathrm{ESRD}$ at one year was 34 $(28.6 \%)$ and was significantly associated with activity $(\mathrm{OR}=1.6, \mathrm{P}=0.025)$, chronicity indices $(\mathrm{OR}=1.82$, $\mathrm{P}=0.007)$ and non-response $(\mathrm{OR}=8.01, \mathrm{P}=0.021)$. Mortality at one year was $18.1 \%$.
\end{abstract}

Conclusion: Repeat biopsy for disease flare showed fewer changes in histological pattern and change in treatment. Treatment response was poor with high mortality. 


\title{
ABSTRACTS OF THE SOUTH AFRICAN RENAL SOCIETY (SARS) 2016 CONGRESS (CAPE TOWN 9-11 SEPTEMBER 2016)
}

\section{ORAL PRESENTATION ABSTRACTS}

Adult and paediatric nephrology session, 11 September, 2016, 09:15 - 09:30

\section{The Protective Role of Toll-Like Receptor-4 Polymorphisms for Susceptibility to Subclinical Atherosclerosis in Black South African CKD Patients}

\begin{abstract}
Muzamil Hassan ${ }^{1,5}$, Raquel Duarte ${ }^{2}$, Caroline Dickens², Therese Dix-Peek ${ }^{2}$, Sagren Naidoo ${ }^{1}$, Ahmed Vachiat ${ }^{3}$, Sacha Grinter ${ }^{3}$, Pravin Manga ${ }^{3}$ and Saraladevi Naicker ${ }^{4}$

${ }^{1}$ Divisions of Nephrology, Department of Internal Medicine, Faculty of Health Sciences, University of the Witwatersrand, South Africa; ${ }^{2}$ Internal Medicine Research Laboratory, Department of Internal Medicine, Faculty of Health Sciences, University of the Witwatersrand, South Africa; ${ }^{3}$ Division of Cardiology, Department of Internal Medicine, Faculty of Health Sciences, University of the Witwatersrand, South Africa; ${ }^{4}$ Department of Internal Medicine, Faculty of Health Sciences, University of the Witwatersrand, South Africa; ${ }^{5}$ Renal Unit, Department of Medicine, Obafemi Awolowo University Teaching Hospital Complex, Ile-Ife, Osun State, Nigeria
\end{abstract}

\begin{abstract}
Background: Toll-like receptor-4 (TLR4) is a major receptor for lipopolysaccharide and other ligands potentially involved in the pathogenesis of inflammation. Polymorphism in the TLR4 gene has been associated with reduced carotid intima-media thickness (CIMT) in healthy individuals. We determined whether TLR4 polymorphisms were related to systemic inflammation and atherosclerosis among South African chronic kidney disease (CKD) patients.

Methods: DNA samples of 155 participants (115 CKD patients and 40 controls) were genotyped for TLR4 polymorphisms (Asp299Gly and Thr399Ile) using polymerase chain reaction and restriction fragment length polymorphism analysis. Serum interleukin-8 (IL-8), monocyte chemoattractant protein-1 (MCP-1) and soluble CD14 (sCD14) levels were measured using a Luminex multiplex assay kit, and CIMT was assessed by B-mode ultrasonography.

Results: In the CKD patients, heterozygous Asp299Gly and Thr399Ile alleles were present in 7 and 5 patients respectively for allelic frequency of 3\% and 2.2\% respectively. In the controls, 3 were heterozygous for the Asp299Gly allele (allelic frequency of 3.8\%) while 2 had heterozygous Thr399Ile allele (allelic frequency of 1.2\%). Cosegregation of the Asp299Gly and Thr399Ile alleles was observed in 5 patients and 1 healthy control, and none of the patients or controls had homozygous Asp299Gly or homozygous Thr399Ile alleles. The TLR4 polymorphisms were associated with the female gender (Asp299Gly allele: $\mathrm{P}=0.038, \chi^{2}=4.29$; Thr399Ile allele: $\mathrm{P}=0.017, \chi^{2}=5.70$ ). Compared with the carriers of the wild-type TLR4, CKD patients with only the Asp299Gly allele and those with the combined Asp299Gly/Thr399Ile alleles had significantly lower levels of inflammatory cytokines and reduced CIMT values. However, no association was observed between TLR4 polymorphisms and traditional risk factors for atherosclerosis.
\end{abstract}


Conclusion: The presence of the Asp299Gly and/or Thr399Ile alleles of TLR4 gene seems to protect South African CKD patients against the development of systemic inflammation and atherosclerosis. TLR4 polymorphisms appear to exact a major influence on the development of atherosclerosis in female CKD patients. 


\title{
ABSTRACTS OF THE SOUTH AFRICAN RENAL SOCIETY (SARS) 2016 CONGRESS (CAPE TOWN 9-11 SEPTEMBER 2016)
}

\section{ORAL PRESENTATION ABSTRACTS}

Adult and paediatric nephrology session, 11 September, 2016, 09:30 - 09:45

\section{Clinical Profile and Outcome of Biopsy Proven Acute Interstitial Nephritis of Native Kidneys at the Groote Schuur Hospital: A 10-year review}

\author{
Emmanuel Effa ${ }^{1,2}$, Brian Rayner ${ }^{1}$, Udeme Ekrikpo ${ }^{1}$, Ikechi Okpechi ${ }^{1}$ \\ ${ }^{1}$ Division of Nephrology and Hypertension, University of Cape Town; ${ }^{2}$ Department of Medicine, University of Calabar, \\ Calabar, Nigeria
}

\begin{abstract}
Background: Acute interstitial nephritis (AIN) is a relatively common cause of acute often reversible kidney injury characterised histopathologyically by inflammatory infiltrates and oedema in the interstitium as well as tubulitis. In South Africa, even with high prevalence of the human immunodeficiency virus (HIV) and tuberculosis infections, and the resultant use of multiple medications, there are scarcely any studies on the clinical profile and outcomes of patients with biopsy proven AIN.

Methods: Retrospective audit of records of patients with biopsy proven AIN of native kidneys seen at the Groote Schuur Hospital, Cape Town between January 2004 and December 2015.

Results: A total of 56 patients - consisting of 29 females and 27 males with biopsy proven AIN were reviewed. The majority were blacks with HIV and HIV-TB co-infection as the most common co-morbidities in $42.8 \%$ and $30.5 \%$ of patients respectively. Drug related AIN was seen in 38 (67.9\%) patients with Rifampicin as the most often implicated medication. Probable drug-related AIN was seen in $3(5.4 \%)$ patients, infection-related AIN in 8 (14.3\%), and unspecified causes in 7 (12.5\%). The diagnosis of AIN was suspected in $44.6 \%$ of all patients before biopsy. In terms of intervention, 18 $(32.1 \%)$ patients had hemodialysis while $24(42.8 \%)$ received steroids. Complete renal recovery at 30 and 90 days was seen in $11 / 44(25 \%)$ patients and $11 / 30$ (36.7\%) patients respectively. There was no correlation between the degree of interstitial inflammation and serum creatinine at biopsy $(p=0.45)$ as well as the presence of co-morbidities and severity of renal failure at presentation $(\mathrm{p}=0.10)$.
\end{abstract}

Conclusion: Recovery was incomplete in a substantial number of patients. Anti-tuberculous drugs are the leading cause of AIN in our setting. Acute interstitial nephritis should reasonably be suspected as a cause of renal failure in this era of multiple co-morbidities requiring an array of medications. 


\title{
ABSTRACTS OF THE SOUTH AFRICAN RENAL SOCIETY (SARS) 2016 CONGRESS (CAPE TOWN 9-11 SEPTEMBER 2016)
}

\section{ORAL PRESENTATION ABSTRACTS}

Adult and paediatric nephrology session, 11 September, 2016, 09:45 - 10:00

\section{Early Detection and Prevention of CKD Progression (CKD-P) in South Africa: The National Kidney Foundation of South Africa (NKFSA) Schools Survey (2016)}

\author{
AM Meyers ${ }^{1}$, JJS du Toit ${ }^{2}$, M Davis ${ }^{3}, \mathrm{~J} \mathrm{Bezuidenhout}^{4}$ \\ National Kidney Foundation of South Africa', University of the Witwatersrand; National Kidney Foundation of South Africa ${ }^{2}$; \\ University of the Witwatersrand'; Mseleni Hospital $(K Z N)^{4}$
}

\begin{abstract}
Background: SA 2014 registry suggests that our most common cause of End Stage Renal Failure (ESRF) is primary hypertension (HT). Therefore this study will survey Grade 11/12 learners (SL) in all SA provinces with the aim of identifying SL with HT plus "at risk" families so as to prevent/delay CKD progression, cardiovascular disease (CVD) and stroke.

Methods: SL in two truly rural KZN schools (group 1) were lectured on kidney matters and then surveyed for FH of HT and/or diabetes, demographic data, BMI, waist measurements and multiple BPs after a 30-minute rest. Urine samples tested excluded menstruating females. Birth weights sought but not obtained. Any abnormalities were referred to a doctor for confirmation and/or referral note for follow-up. Results were standardised for age and sex; HT defined at the $95^{\text {th }}$ percentile. The "at risk" groups: (a) hypertensive school learners (SL) with family history (FH) of HT; (b) SLHT with no FHHT; and (c) normo-tensive (NT) SL with FHHT. Results were compared with five urban/peri-urban schools (group 2, 2009-11). All SL were black citizens. Appropriate statistical analysis performed and p-value of 0.05 taken as significant. Wits ethics clearance (M160268) included parental and SL consent.

Results: Group 1: $\mathrm{n}=238$ (136=f; 102=m); average age 18.5years (15-26). Group 2: $\mathrm{n}=946$ (427=f; $519=\mathrm{m})$; average age $17.6 \mathrm{y}$ ears $(15-20)$. SLHT group 1 vs group $2(\mathrm{p}<0.0): 5 \mathrm{f}(3.8 \%)$ vs $52(12.2 \%)$; $14 \mathrm{~m}(13.5 \%)$ vs $83(16 \%)$.

Total increased BP: Systolic $=7.8 \%$; Diastolic $=4 \%$; both $18 \%$. In HT vs NT BMI showed better correlation $\left(\chi^{2}=5.79 ; \mathrm{p}=0.015\right)$ than waist measurements $\left(\chi^{2}=3.14 ; \mathrm{p}=0.04\right)$. "At risk" cohorts shown in 93 group $1(39 \%)$ vs 174 group $2(21 \%)(\mathrm{p}<0.05)$.

Group 1 dipsticks showed 13(5.5\%) (12f; $1 \mathrm{~m})$ UTIs; protein \pm haematuria in 4(1.7\%) (glomerulonephritis); $12(5 \%)$ had haematuria due to prominent bilharzia; 3-4+ glycosuria in $27(20 \mathrm{f} ; 7 \mathrm{~m}-3: 1)$ all non-diabetic.
\end{abstract}


Conclusion: SLHT significantly higher prevalence in urban/peri-urban schools (group 2); especially in $\mathrm{f}$. "At risk" factors found in $20-40 \%$ of total SLs identify target families for further screening. UTI in 9\% women may present risk in later pregnancy associated oligonephronia. Glycosuria - Fanconi syndrome; 3f:1m ratio fits etiology of "Mseleni joint disease".

Downside of study: no birth weights; no district nurses present to manage referrals. Altered protocol will rectify these issues. 


\title{
ABSTRACTS OF THE SOUTH AFRICAN RENAL SOCIETY (SARS) 2016 CONGRESS (CAPE TOWN 9-11 SEPTEMBER 2016)
}

\section{ORAL PRESENTATION ABSTRACTS}

Rcssa future of nephrology, 11 September, 2016, 09:15 - 10:00

\section{The Discovery Health KidneyCare Programme}

\author{
Dr E Gottlich \\ ${ }^{1}$ Discovery Health; ${ }^{2}$ Morningside Children's Kidney Treatment Centre; ${ }^{3}$ University of Witwatersrand Donald Gordon Medical \\ Centre; ${ }^{4}$ Department of Paediatrics and Child Health, University of Pretoria
}

\begin{abstract}
Background: The annual increase in people requiring renal replacement therapy worldwide is estimated to be $8 \%$, which is far in excess of the global population growth rate of $1.3 \%$. This accounts for $>850,000$ deaths globally and is the $12^{\text {th }}$ leading cause of death. The increase is driven in SA due to an increasing incidence and prevalence of diabetes, hypertension, HIV and an ageing population. Adding to the increasing number and related costs of patients on chronic dialysis is the dropping transplantation rate. It is estimated that about 50,000 SA citizens require chronic renal replacement therapy. Currently about 8,500 patients are dialysed in both private and state sectors in SA. The limited number of specialist physicians and nephrologists in SA caring for chronic dialysis patients are not able to adequately manage this increasing group of patients thus creating a risk of poor quality of care and poor quality of life due to increased morbidity and mortality. The chronic dialysis environment in SA is unregulated and limited audits exist of processes of care and quality of care clinical outcomes. The KidneyCare Programme is a Discovery Health initiative that has been developed over the last 10 years. Aims: The aims of this study were to ensure co-ordinated and joint participation by patients, doctors and dialysis care providers to improving quality of care; to improve the quality of life for patients on chronic dialysis and reduce additional costs incurred caused by repeat hospital admissions and avoidable complications; and to standardise the pathology requirements of patients on chronic dialysis and ensure compliance to testing.

Methods: To measure and report on the comprehensive management of the patient in order to institute targeted improvement of care programmes. Implementation of these programmes are the primary responsibility of the attending doctor and the provider of dialysis services, and to provide educational material to patients.
\end{abstract}

Results: The processes of care amongst patients was 69\%. With regards to clinical outcomes, mortality was 8.96\% (Phase 9, 2014, KidneyCare patients in the period). Admission rate: The average annual renal related admissions per patient was 1.44 , while the overall average annual admissions per patient (all cause) was 2.38. Length of stay: The average annual renal related bed days per admission was 5.00, while the overall average annual bed days per admission (all cause) was 5.32 . 


\title{
ABSTRACTS OF THE SOUTH AFRICAN RENAL SOCIETY (SARS) 2016 CONGRESS (CAPE TOWN 9-11 SEPTEMBER 2016)
}

\section{ORAL PRESENTATION ABSTRACTS}

Combined session, 11 September, 2016, 10:30 - 10:45

\section{Long-term Outcomes in Accepted Living Kidney Donors at Charlotte Maxeke Johannesburg Academic Hospital (1983- 2015)}

\author{
C Dayal ${ }^{1}$, N Diana ${ }^{1,2}$, M Davies ${ }^{1,2}$, AM Meyers ${ }^{3}$, G Paget ${ }^{1,2}$ \\ ${ }^{1}$ Department of Internal Medicine, Faculty of Health Sciences, University of Witwatersrand, South Africa; ${ }^{2}$ Department of \\ Internal Medicine, Division of Nephrology, Faculty of Health Sciences, University of Witwatersrand, South Africa; ${ }^{3}$ Emeritus \\ Professor of Medicine in the Faculty of Health Sciences, University of Witwatersrand, South Africa and Chairman of the \\ National Kidney Foundation.
}

\begin{abstract}
Background: Emerging data suggests the risk of adverse outcomes in kidney donors may have been underestimated. There is a paucity of data regarding outcomes in Accepted Living Donors (ALDs) among demographically diverse populations.

Methods: A retrospective review of 298 ALDs attending the Charlotte Maxeke Johannesburg Academic Hospital Living Donor Clinic over a 32-year period was undertaken. Of the total number of ALDs, 11 were excluded due to unavailable pre-donation parameters. The following data was collected: predonation and post-donation (at first visit, 1 year later, and most recent visit) blood pressure (BP), albumin-excretion-rate (AER), creatinine and CKD-EPI eGFR. Mortality data was noted.

Results: Median follow-up time was 44 months (IQR 13.8-93.5 months). Hypertension was documented in $12.8 \%$ of ALDs at most recent follow-up compared to $4.7 \%$ of ALDs pre-donation $(\mathrm{p}=0.06)$. There was a significant increase in AER between pre-donation and post-donation (most recent) visit $(\mathrm{p}<0.001)$. There was a significant decline in CKD-EPI eGFR between pre-donation $\left(91.7 \pm 19.1 \mathrm{ml} / \mathrm{min} / 1.73 \mathrm{~m}^{2}\right)$ and most recent visit post-donation $\left(72.5 \pm 20 \mathrm{ml} / \mathrm{min} / 1.73 \mathrm{~m}^{2}\right)$ visits $(\mathrm{p}<0.001)$. Of the ALDs $25 \%$ had a CKD-EPI eGFR $<60 \mathrm{ml} / \mathrm{min} / 1.73 \mathrm{~m}^{2}$ at most recent visit $(\mathrm{p}=0.02)$. No ALDs required institution of renal replacement therapy (RRT). There were 5 documented deaths, 1 in the peri-operative period, and the remaining 4 were trauma related. Black ethnicity was not associated with increased risk of adverse outcome.
\end{abstract}

Conclusion: Our data assesses the safety of living kidney donation in the South African population but is limited by high rates of donor follow-up defaulting. While there was a significant increase in the AER over time, the post-donation (most recent visit) AER was still within normal limits. There is concern that $25 \%$ of the ALDs developed an eGFR $<60 \mathrm{ml} / \mathrm{min}$, however none have required RRT at last follow-up. 


\title{
ABSTRACTS OF THE SOUTH AFRICAN RENAL SOCIETY (SARS) 2016 CONGRESS (CAPE TOWN 9-11 SEPTEMBER 2016)
}

\section{ORAL PRESENTATION ABSTRACTS}

Combined session, 11 September, 2016, 10:45 - 11:00

\section{Quality of Life in Patients on Chronic Dialysis in South Africa: A Comparative Mixed Methods Study}

\author{
Elliot K Tannor ${ }^{1}$, Elize Archer ${ }^{2}$, Kenneth Kapembwa ${ }^{1}$, Susan C van Schalkwyk ${ }^{2}$, M Razeen Davids ${ }^{1}$ \\ ${ }^{1}$ Division of Nephrology, Department of Medicine, Stellenbosch University and Tygerberg Hospital, Cape Town, South Africa; \\ ${ }^{2}$ Centre for Health Professions Education, Stellenbosch University, Cape Town, South Africa
}

\begin{abstract}
Background: The increasing prevalence of treated ESRD and low transplant rates in Africa leads to longer durations on dialysis. Dialysis should not only be aimed at prolonging lives but also improving the quality of lives (QOL). Using mixed methods, we investigated the QOL of patients on chronic hemodialysis (HD) and peritoneal dialysis (PD).

Methods: We conducted a cross-sectional study at Tygerberg Hospital in Cape Town, South Africa. The KDQOL-SF 1.3 questionnaire was used for the quantitative phase. Focus-group interviews were then conducted by an experienced facilitator in groups of HD and PD patients. Electronic recordings were transcribed verbatim and analysed manually to identify emerging themes.

Results: A total of 106 patients completed questionnaires and 36 of them participated in the focusgroup interviews. There was no difference between PD and HD patients in the overall KDQOL-SF scores. PD patients scored lower with regard to symptoms $(\mathrm{p}=0.005)$, energy/fatigue $(\mathrm{p}=0.025)$ and sleep $(p=0.023)$ but scored higher for work status $(p=0.005)$ and dialysis staff encouragement $(p=0.019)$ than those on HD. Symptoms and complications were verbalised more in the PD patients with fear of peritonitis keeping some housebound. PD patients were more limited by their treatment modality which impacted on body image, sexual function and social interaction, but there were less dietary and occupational limitations. Patients on each modality acknowledged the support received from family and dialysis staff, but highlighted the lack of support from government. PD patients had little opportunity for interaction with one another and therefore enjoyed less support from fellow patients.
\end{abstract}

Conclusion: PD patients experienced a heavier symptom burden and greater limitations related to their dialysis modality, especially with regards to social functioning. The study has identified several issues affecting quality of life which we are able to address. 


\title{
ABSTRACTS OF THE SOUTH AFRICAN RENAL SOCIETY (SARS) 2016 CONGRESS (CAPE TOWN 9-11 SEPTEMBER 2016) \\ POSTER PRESENTATIONS ABSTRACTS
}

\section{P01 - Outcome of Renal Transplantation in Patients with Lupus Nephritis: A Single Centre Study in Cape Town}

\author{
A Almradi ${ }^{1}, \mathrm{U}^{\text {Ekrikpo }}{ }^{1}, \mathrm{IG}$ Okpechi $^{1}$ \\ ${ }^{1}$ Division of Nephrology and Hypertension, Groote Schuur Hospital and University of Cape Town
}

\begin{abstract}
Background: Lupus nephritis (LN) occurs in up to $50-70 \%$ of patients with systemic lupus erythematosus (SLE). Although most LN patients are suitable for renal transplantation when they develop end-stage renal disease (ESRD), the risk of recurrence of LN post-transplantation can be as high as 30\%. The outcome of transplanted LN patients has not been adequately studied in South Africa.

Methods: The study was designed as a retrospective descriptive study of patients transplanted in the renal unit at Groote Schuur Hospital, Cape Town from 1 January, 2004 to 31 December, 2013.

Results: There were 454 patients who were transplanted in the study period of which 15/454 (3.3\%) had LN. The M:F ratio of LN patients was 1:14, mean age was $25 \pm 10$ years, all were known with Class IV LN and 10/15 (66.7\%) were transplanted from a cadaveric donor. Immunosuppression was initiated in $7 / 15(46.7 \%)$ with combination of cyclosporine and azathioprine; in 2/15 (13.3\%) with tacrolimus and azathioprine, and in 6/15 (40.0\%) with tacrolimus and MMF. Recurrence of $\mathrm{LN}$ was seen in 1 patient $(6.7 \%)$ who developed Class V LN. Graft rejection was diagnosed in 10/15 cases $(66.7 \%)$ with types of rejection noted to be acute cellular rejection in $6 / 15(40 \%)$, antibody mediated rejection in $1 / 15$ (6.7\%), and chronic rejection in 3/15 (20\%). ESRD occurred in 3 patients $(20 \%)$ with causes from antibody mediated rejection (6.7\%), chronic allograft nephropathy $(6.7 \%)$, and renal artery thrombosis (6.7\%). Mean time to ESRD was 16.0 months. A total of 5 deaths $(33.3 \%)$ occurred from sepsis in $3 / 15$ $(20 \%), 1 / 15(6.7 \%)$ from pulmonary embolism, and 1/15 (6.7\%) from progressive ESRD after denial of dialysis. Mean time to death was 44.1 months.
\end{abstract}

Conclusion: Outcome of transplanted LN patients is not dissimilar to those of patients without LN in Cape Town. Further studies are needed to enable us improve outcomes and to better understand factors associated with outcome in these patients. 


\title{
ABSTRACTS OF THE SOUTH AFRICAN RENAL SOCIETY (SARS) 2016 CONGRESS (CAPE TOWN 9-11 SEPTEMBER 2016)
}

\section{POSTER PRESENTATION ABSTRACTS}

\section{P02 - A Study of Factors Affecting the Progression of Chronic Kidney Disease beyond Ace Inhibition in KwaZulu-Natal, South Africa}

\author{
Verushka Reddy, Nomandla Madala, Alain Assounga \\ Department of Nephrology, Nelson R. Mandela School of Medicine, University of KwaZulu-Natal, Durban, South Africa
}

\begin{abstract}
Background: Chronic kidney disease (CKD) is on the rise worldwide. It is associated with increased morbidity and mortality, and places a huge burden on cost constrained health systems in developing countries such as South Africa. ACE inhibition is well established as a major factor of reduction of the decline of renal function.

Methods: This is a retrospective cohort study using the medical records of 300 patients attending the outpatient renal clinic department at Inkosi Albert Luthuli Central Hospital for the period January 2007 to December 2009. The patients were followed up for 24 months following their first clinic visit. Sociodemographic (age sex, residence) and clinical characteristics including eGFR, blood pressure, BMI (body mass index), proteinuria, haemoglobin, cholesterolemia, uricaemia were recorded. Treatments received including ACE inhibitors, statins, non-dihydropyridine calcium channel blockers (NDCCB), and Beta blockers were also recorded. Patients were divided into two outcome categories, according to changes in eGFR (estimated glomerular filtration rate): patients with eGFR decline of $1 \mathrm{ml} / \mathrm{min} /$ year or less and those with accelerated eGFR decline $(>1 \mathrm{ml} / \mathrm{min} /$ year). Data analysis using SPSS version 23 (IBM) comprised of descriptive tests and logistic regression analysis (expressed as OR (odd ratio) and confidence interval) for the study of the association of above characteristics with patients' outcome.

Results: ACE inhibition was used by $92 \%$ of the patients. Uricaemia and BMI were associated with worsening of eGFR decline OR: 1.012[1.003-1.020] $\mathrm{p}=0.007$ and OR: 3.775[1.116-12.766], $\mathrm{p}=0.033$ respectively. The use of carvedilol and NDCCB was associated with a reduction of the decline of eGFR with OR: $0.144[0.207-0.953] \mathrm{p}=0.037$ and OR: 0.543 [0.329-0.884], $\mathrm{p}=0.016$ respectively. No significant association was found between eGFR change and daily proteinuria or cholesterolemia.
\end{abstract}

Conclusion: These results suggest that beyond ACE inhibition, the control of uricaemia, BMI, and use of carvedilol and NDCCB may lead to a further delay in the progression of chronic kidney disease in KwaZulu-Natal. 


\title{
ABSTRACTS OF THE SOUTH AFRICAN RENAL SOCIETY (SARS) 2016 CONGRESS (CAPE TOWN 9-11 SEPTEMBER 2016)

\author{
POSTER PRESENTATION ABSTRACTS
}

\section{P03 - Association between Biochemical Markers of Mineral Bone Disorder and Mortality in Maintenance Hemodialysis Patients}

\author{
Bala Waziri ${ }^{1}$, Raquel Duarte ${ }^{1}$, Saraladevi Naicker ${ }^{1}$ \\ ${ }^{1}$ Department of Internal Medicine, Faculty of Health Sciences, University of the Witwatersrand, Johannesburg, South Africa
}

\begin{abstract}
Background: Studies have shown an increased mortality risk in patients with abnormal biochemical markers of mineral bone disorder. These studies, mainly from developed countries, have revealed higher levels of intact parathyroid hormone, calcium, phosphate and alkaline phosphatase as independent predictors of mortality. Data on the existence of this link in African hemodialysis patients are rare. Therefore, the aim of this study was to assess the impact of serum total alkaline phosphatase (TAP) on mortality in maintenance hemodialysis (MHD) patients.

Patients and Methods: This study enrolled a total of 223 patients on MHD from two dialysis centres in Johannesburg between January 2009 and March 2016. Patients were categorised into low TAP group $(<112 \mathrm{U} / \mathrm{L})$ versus high TAP group $(\geq 112 \mathrm{U} / \mathrm{L})$ based on median TAP of $112 \mathrm{U} / \mathrm{L}$. By multivariate cox regression analysis the impact of serum TAP on primary outcome (death) was assessed.

Results: The MHD patients (147 men, 76 women) had a mean age of $54.5 \pm 15.6$ years with a median dialysis vintage of 24 months (IQR, 12-48) and a mean kt/V (single pool) of $1.4 \pm 0.3$. During a period of seven years there were $52(23.3 \%)$ deaths. After adjusting for cofounders such as age, other makers of bone disorder, Alanine transaminase and co-morbidity (diabetes mellitus), patients in the high TAP group had a significant higher risk of death compared to patients in the low TAP group (hazard ratio, 2.6, $95 \%$ CI 1.23-5.45, $\mathrm{p}=0.01)$. Similarly, corrected calcium $<2.75 \mathrm{mmol} / \mathrm{L}$ was associated with a lower risk of death compared to patients with calcium $\geq 2.75 \mathrm{mmol} / \mathrm{L}$ ( $\mathrm{HR}=0.18,95 \%$ CI $0.04-0.95, \mathrm{p}=0.04$ ). TAP correlated significantly with PTH $(r=0.3 ; \mathrm{P}<0.001)$.
\end{abstract}

Conclusion: High levels of serum alkaline phosphate are associated with an increased risk of death in MHD patients. This relatively inexpensive test may be utilised as a surrogate marker for monitoring treatment in End-stage Renal Disease. 


\title{
ABSTRACTS OF THE SOUTH AFRICAN RENAL SOCIETY (SARS) 2016 CONGRESS (CAPE TOWN 9-11 SEPTEMBER 2016)
}

\section{POSTER PRESENTATION ABSTRACTS}

\section{P04 - Clinico-pathological Characteristics and Outcomes of Patients with IgA and Non-IgA Mesangioproliferative Glomerulonephritis (MPGN) in Cape Town: A Single Centre Study}

\author{
Z Barday, IG Okpechi \\ Division of Nephrology and Hypertension, University of Cape Town
}

\begin{abstract}
Background: Glomerular diseases constitute the leading cause of end-stage kidney disease (ESRD) in Africa. Non-IgA type mesangial proliferative GN (MPGN) is a common cause of nephrotic syndrome in Cape Town. There is little long-term outcome data on non-IgA type MPGN and IgA type MPGN (IgAN) in South Africa.

Methods: This was a 10-year retrospective analysis of patients with primary MPGN at GSH. The patterns were divided into non-IgA MPGN or IgAN. Primary outcome of interest was ESRD while secondary outcome was complete remission at the last visit. Data of non-IgA MPGN was compared with IgAN. Univariate cox regression analysis was used to determine factors associated with ESRD. Significant p-value was taken as $<0.05$.

Results: Overall, there were 109 patients with mean age of $33.8 \pm 14.9$ years, $53.2 \%$ were males, $39.4 \%$ were black Africans, $58.7 \%$ presented with nephrotic syndrome and $20.2 \%$ had IgAN. Compared to the non-IgA group, most patients with IgAN were not treated with immunosuppression (72.7\% vs $40.2 \%$; $\mathrm{p}=0.006)$. Overall, $10.1 \%$ reached ESRD at the last visit (IgAN: $40.9 \%$ vs non-IgAN: $2.3 \%$; $<<0.0001)$ and $30.2 \%$ were in complete remission (IgAN: 9.1\% vs non-IgAN: 35.7\%; $\mathrm{p}=0.015$ ). Overall, mean ESRD-free survival time was 98.1 months (95\% CI: 87.1-109.2 months) with five-year ESRD-free survival of $86.4 \%$. The five-year ESRD-free survival for non-IgAN and IgAN, respectively, were: $97.6 \%$ vs $63.3 \%, \log$ rank $\mathrm{p}=0.001)$. Hypertension $(\mathrm{p}=0.019)$ and not receiving immunosuppression $(\mathrm{p}=0.046)$ were significant predictors of progression to ESRD. IgAN patients had a higher risk of progressing to ESRD than non-IgAN patients (HR: 8.6; 95\% CI: 1.8-40.7; $\mathrm{p}=0.007$ ).
\end{abstract}

Conclusion: Renal survival of primary non-IgA MPGN is significantly higher than for IgAN in our centre. The poor outcome of IgAN may be related to non-immunosuppressive therapy and less aggressive blood pressure control. Prospective studies are needed to adequately assess these factors. 


\title{
ABSTRACTS OF THE SOUTH AFRICAN RENAL SOCIETY (SARS) 2016 CONGRESS (CAPE TOWN 9-11 SEPTEMBER 2016) \\ POSTER PRESENTATION ABSTRACTS
}

\section{P05 - Metabolic Syndrome and Cardiovascular Risk in HIV- infected Black South Africans after five years of Effective ART: Preliminary Results}

\author{
M Borkum ${ }^{1}$, J Heckmann ${ }^{2}$, K Manning ${ }^{3}$, J Dave ${ }^{4}$, N. Levitt ${ }^{4}$, N Wearne ${ }^{1}$ \\ Department of Nephrology and Hypertension, University of Cape Town/Groote Schuur Hospital, South Africa ${ }^{1}$; Division of \\ Neurology, University of Cape Town/Groote Schuur Hospital, South Africa' ${ }^{2}$; Division of Biostatistics, University of Cape \\ Town ${ }^{3}$; Department of Endocrinology and Metabolism, University of Cape Town/Groote Schuur Hospital, South Africa ${ }^{4}$
}

\begin{abstract}
Background: HIV-infected individuals are living longer on ART. The overlapping mechanisms of chronic inflammation, oxidative stress, endothelial dysfunction and the metabolic effects of ART are thought to increase the prevalence of metabolic complications in these individuals despite virological supression. Little is known about how the interplay between inflammation and ageing affects HIVinfected South Africans on effective ART.

Methods: This is an extension of a prospective longitudinal study investigating the metabolic complications of ART in HIV-infected South Africans. Participants are being recalled after $\geq 5$ years on ART. Study assessments include measurements of: 24-hour ABPM, Sphygmacor data, fasting lipogram, oral glucose tolerance test, high-sensitivity C-reactive Protein (hsCRP) and anthropometric data. CD4counts and viral loads were obtained from the national lab results system.

Results: Of the 50 subjects recruited, $90 \%(n=45)$ were female with a median age of 41.5 years. Of the females, $62 \%(n=31)$ were overweight or obese by standard BMI categories and $78 \%(n=35)$ had abdominal obesity (waist circumference of $>80 \mathrm{~cm}$ according to local definitions). A total of $52 \%$ of patients $(n=26)$ had $\geq 2$ of the five metabolic syndrome features and $12 \%(n=6)$ had $\geq 3$. The median CD4-count was 521 cells $/ \mathrm{mm}^{3}$ and $84 \%$ were virologically supressed. Of the patients, $88 \%$ had raised hsCRP and an increased waist circumference, in the females, was associated with an increased waist circumference $(\mathrm{p}=0.005)$. Overall, $61 \%$ of the cases were non-dippers and non-dipping did not associate with increased waist circumference $(\mathrm{p}=0.131)$. Compared to normative values for age, the HIV-positive population had higher central aortic systolic pressures across all age categories. Other sphygmacor measures of aortic stiffness were similar to an age matched reference population.
\end{abstract}

Conclusion: Our cohort of HIV-positive black African women, on effective ART and predominantly under 50 years old, demonstrate evidence of vascular stiffness, ABPM non-dipping and ongoing inflammation. This is likely to have implications for cardiovascular risk longterm. 


\title{
ABSTRACTS OF THE SOUTH AFRICAN RENAL SOCIETY (SARS) 2016 CONGRESS (CAPE TOWN 9-11 SEPTEMBER 2016) \\ POSTER PRESENTATION ABSTRACTS
}

\section{P06 - Comparison of two Phosphate Binders on Bone Disease Markers in End-stage Renal Failure Patients}

\author{
Susanna Maria Botha ${ }^{1}$, Elmien van den Heveer-Kriek ${ }^{1}$, Christelle Filmalter ${ }^{2}$ \\ ${ }^{1}$ Department of Health Sciences, Central University of Technology; ${ }^{2}$ Fresenius Medical Care SA (Pty) Ltd, Western Cape
}

\begin{abstract}
Background: Phosphate binders are recommended medication for treatment of hyperphosphatemia in ESRD patients on hemodialysis. It is indicated for the control of serum phosphate levels that dialysis in combination with a renal diet cannot maintain at recommended serum levels. Calcium-based phosphate binders such as calcium acetate and calcium carbonate are common phosphate binders prescribed in the industry. This study compared the effectiveness of two phosphate binders, investigating bone disease markers over a period of 26 months.

Methods: A total of 70 patients were identified that fit the inclusion criteria. Each patient controlled him- or herself. Patients received the calcium carbonate in the first 12 months, then were switched to the calcium acetate in the subsequent 12 months. Bone disease markers (serum calcium, phosphate and parathyroid hormone) were compared after 24 months.

Results: No statistical significant difference was observed when serum corrected calcium, PTH and albumin were compared. However, a statistical significant difference was observed in the comparison of the mean serum phosphate level in the calcium acetate group which was $2.00 \mathrm{mmol} / \mathrm{L}(\mathrm{min} 0.77 \mathrm{mmol} / \mathrm{L}$ - $\max 2.98 \mathrm{mmol} / \mathrm{L}$ ) compared to that of the mean phosphate level in the calcium carbonate group of $1.81 \mathrm{mmol} / \mathrm{L}(\min 0.83 \mathrm{mmol} / \mathrm{L}-\max 3.37 \mathrm{mmol} / \mathrm{L}), \mathrm{p}=0.02$.
\end{abstract}

Conclusion: Calcium carbonate showed to be the more effective phosphate binder in this study, specifically pertaining to serum phosphate. The serum calcium and PTH levels in both groups were within the recommended ranges (KDOQI). 


\title{
ABSTRACTS OF THE SOUTH AFRICAN RENAL SOCIETY (SARS) 2016 CONGRESS (CAPE TOWN 9-11 SEPTEMBER 2016)
}

\section{POSTER PRESENTATION ABSTRACTS}

\section{P07 - Lupus Nephritis at Tygerberg Hospital: An experience over three decades}

\author{
$\mathrm{U}^{\text {Brijlal }}{ }^{1}$, WD Bates ${ }^{2}$, MR Moosa ${ }^{1}$ \\ ${ }^{1}$ Department of Medicine and ${ }^{2}$ Department of Anatomical Pathology, University of Stellenbosch and Tygerberg Academic \\ Hospital
}

\begin{abstract}
Background: Systemic lupus erythematosus (SLE) is a multisystem disease with serious complications, including lupus nephritis. SLE is particularly prevalent in the Western Cape, and predominantly affects women in the prime of their lives. Renal biopsy is an important tool for the management of the lupus patient with kidney disease as it guides treatment and is of great prognostic importance. Various classifications have been employed over the years and the current classification, accepted widely, is the ISN/RPS 2003 Classification of Lupus Nephritis.

Aims: To ascertain if there has been a change in the spectrum of renal pathology, demographics, patient characteristics, as well as the long-term outcomes in patients with lupus nephritis over three decades.

Methods: This is a retrospective review of 315 records of SLE patients with suspected renal disease who underwent renal biopsy in our department at Tygerberg Hospital between 1 January,1983 and 31 December, 2012.

Results: Class IV LN consistently remained the most common pattern throughout the three decades. We noted an increase in the trend of Class III lupus nephritis (LN) and Class V LN over the three decades, as well as a decrease in Class II LN. Mortality in our cohort was associated with hypertension, end-stage renal disease (ESRD), decreased C3 levels, high activity, and chronicity scores at initial biopsy on univariate analysis. The overall five-year survival for this cohort was $67 \%$ (95\% CI, 60-72\%).
\end{abstract}

Conclusion: We confirm that Class IV LN is the most frequent class occurring in our cohort of patients at Tygerberg Hospital and had the poorest survival rates compared to the other classes. SLE, in our experience, is an aggressive disease and renal involvement carries a grave prognosis, in line with reports from other centres in South Africa. The prognosis is considerably worse than that reported elsewhere in the world. 


\title{
ABSTRACTS OF THE SOUTH AFRICAN RENAL SOCIETY (SARS) 2016 CONGRESS (CAPE TOWN 9-11 SEPTEMBER 2016) \\ POSTER PRESENTATION ABSTRACTS
}

\section{P08 - Aetiology, Prognostic Factors and Treatment Outcomes of Acute Kidney Injury in Children in a Tertiary Hospital in South Africa}

\author{
MS Choopa $^{1}$, P Becker ${ }^{2}$, G van Biljon ${ }^{1}$ \\ ${ }^{1}$ Paediatric Nephrology Unit, University of Pretoria, Steve Biko Academic Hospital, Pretoria, South Africa; ${ }^{2}$ Biostatistics \\ Research Unit, University of Pretoria, Pretoria, South Africa
}

\begin{abstract}
Background: Few reports on aetiology and outcome of acute kidney injury (AKI) originate from sub-Saharan Africa. This study aimed to determine the aetiology, prognostic factors and treatment outcomes of AKI in children.

Methods: A retrospective file review was done of 63 children with AKI (median age 38.9 months [IQR 1.8-105.9]) referred to the Paediatric Nephrology Unit, Steve Biko Academic Hospital, a tertiary hospital in Pretoria, South Africa, from 2003 to 2016. Features analysed included age, sex, aetiology of AKI, renal function, morbidity, mortality, dialysis requirement and outcome. Patients were categorised as Group 1 (complete/partial renal function recovery without need for continued dialysis), and Group 2 (died/required continuation of dialysis).

Results: Male:female ratio was 2.9:1. The causes of AKI were acute glomerulonephritis 18/63 (29\%), obstructive uropathies 18/63 (29\%), acute tubular necrosis (ATN) associated with hypovolaemia 8/63 $(13 \%)$, sepsis $7 / 63(11 \%)$, toxins $6 / 63(9 \%)$, post-surgery $4 / 63(6 \%)$, and hemolytic uraemic syndrome 2/63 (3\%). Of these children, 31\% developed AKI in hospital. Of those with ATN due to hypovolaemia, $50 \%$ were neonates: $25 \%$ breastfed, $50 \%$ mixed fed. In Group 1, 34/59 (58\%) completely recovered (8 received peritoneal dialysis (PD)), and 25/59 (42\%) had on-going renal impairment. In Group 2, 4/63 (6\%) demised (2 received PD). 60\% of patients with multi-organ failure died.

Conclusion: Acute glomerulonephritis and obstructive uropathies are common causes of AKI in this on-going study. Exclusive breastfeeding becomes a risk factor for the development of AKI in the face of insufficient breast milk.
\end{abstract}

Keywords: Acute kidney injury, children, aetiology, Africa. 


\title{
ABSTRACTS OF THE SOUTH AFRICAN RENAL SOCIETY (SARS) 2016 CONGRESS (CAPE TOWN 9-11 SEPTEMBER 2016) \\ POSTER PRESENTATION ABSTRACTS
}

\section{P09 - The Initiation of a Shared Care and Home Hemodialysis Programme in South Africa}

\author{
C Clark ${ }^{1}$, J Fabian ${ }^{2}$, P Gaylard ${ }^{3}$, I Katz ${ }^{4}$ \\ ${ }^{1}$ National Renal Care; ${ }^{2}$ Wits Donald Gordon Medical Centre; ${ }^{3}$ Data Management and Statistical Analysis; ${ }^{4}$ Department of \\ Renal Medicine, St George Hospital, Sydney, Australia
}

\begin{abstract}
Introduction: A patient's ability to self-manage their disease and dialysis has been shown to benefit patient outcomes. Independence means greater potential for rehabilitation, improved well-being and home or shared care options for chronic dialysis. Home hemodialysis (HHD) and shared care hemodialysis (SC-HD) redefine the nursing role emphasising patient empowerment. In HHD the patient or caregiver dialyses at home and SC-HD offers independence but in a supportive environment. This study describes the initiation of a pilot SC-HD and HHD programme within National Renal Care, South Africa.

Methods: SC-HD includes various therapeutic options in the dialysis unit such as machine preparation, self-needling, self-connection, medication administration, intradialytic monitoring, machine setting and disconnection. The small sample size for HHD precluded statistical analysis. Clinical and laboratory data for SC-HD patients pre- and at six months post-programme initiation were compared using the paired t-test (or the Wilcoxon matched pairs test) for continuous variables and McNemar's test for paired categorical data.

Results: Since the national implementation of the programme in 17 units, 30 SC-HD and 3 HHD patients have participated, with 4 patients discontinuing SC-HD within six months of starting the programme. The mean age of the SC-HD patients was 48 years, $85 \%(n=22)$ were male, $58 \%(n=15)$ were African, and $58 \%(n=15)$ were employed. $77 \%(n=20)$ had hypertensive nephropathy as the cause of ESKD and few had co-morbid disease $(19 \%, n=5)$. The primary form of vascular access was an AVF $(85 \%, \mathrm{n}=22)$. The mean duration on chronic dialysis before initiation on the programme was 4.1 years. No change in the routine laboratory and clinical indicators was seen post initiation of SC-HD. These include blood pressure, pre-dialysis weight, ultrafiltration volumes, electrolytes, and hemoglobin levels.
\end{abstract}

Conclusion: Both SC-HD and HHD programmes offer a safe alternative to ESKD patients. Further studies will include the patient experience, acceptability and sustainability of the SCHD/HHD programme. 


\title{
ABSTRACTS OF THE SOUTH AFRICAN RENAL SOCIETY (SARS) 2016 CONGRESS (CAPE TOWN 9-11 SEPTEMBER 2016) \\ POSTER PRESENTATION ABSTRACTS
}

\section{P11 - Prevalence and Outcome of Antibody-mediated Allograft Injury in a Historical Cohort}

\author{
M Davies ${ }^{1,2}$, S Saffer ${ }^{1}$, F Khan ${ }^{1}$, G Paget ${ }^{1,2}$ \\ ${ }^{1}$ University of the Witwatersrand, Johannesburg; ${ }^{2}$ Division of Nephrology, Charlotte Maxeke Johannesburg Academic Hospital
}

\begin{abstract}
Introduction: Appreciation of the effect of antibody-mediated rejection (ABMR) on long-term renal transplant outcome has historically been limited by the lack of a reliable marker. We reviewed late period for-cause biopsy data from a pre-C4d era cohort to evaluate the contribution of antibodymediated injury (AMI) to graft dysfunction and loss.

Materials and Methods: Late period for-cause biopsies ( $n=162$ ) were re-evaluated for evidence of AMI as per the Banff 2013 definition of C4d-negative ABMR. The effect of AMI on severity of allograft injury and post-biopsy survival was analysed.

Results: AMI was identified in 52 biopsies (32.1\%); with high prevalence observed in cases of contemporaneously diagnosed IFTA/CAN (38.5\%), all rejection $(32.9 \%)$, and CNI nephropathy (21.4\%). Surprisingly, $24.6 \%$ of cell-mediated rejection cases retrospectively evidenced AMI. Creatinine was non-significantly higher $(254.92 \pm 159.50$ vs $232.96 \pm 134.87 \mathrm{mmol} / \mathrm{L}, \mathrm{p}=0.363)$, and UPCR higher (median 0.19, IQR 0.09-0.44 vs median 0.06, IQR 0.02-0.21; $\mathrm{p}=0.022$ ) when evidence of AMI was retrospectively found.

A trend toward poorer graft survival with AMI was observed (Cox-Mantel: $F=1.375, p=0.124)$. When survival analysis was restricted to those cases with contemporaneous diagnoses of non-rejection injury leading to allograft dysfunction, a statistically significant poorer survival was observed in those cases with evidence of AMI at retrospective re-evaluation (Cox-Mantel: $\mathrm{F}=2.851, \mathrm{p}=0.0022$ ).
\end{abstract}

Conclusion: The contribution of AMI to late period graft dysfunction has historically been underappreciated. Its presence is associated with more severe allograft dysfunction (particularly in the form of proteinuria) and portends poorer survival. 


\title{
ABSTRACTS OF THE SOUTH AFRICAN RENAL SOCIETY (SARS) 2016 CONGRESS (CAPE TOWN 9-11 SEPTEMBER 2016) \\ POSTER PRESENTATION ABSTRACTS
}

\section{P12 - Depletion Therapies in Late Period Antibody-mediated Rejection (LPABMR)}

\author{
M Davies ${ }^{1,2}$, G Paget ${ }^{1,2}$ \\ ${ }^{1}$ University of the Witwatersrand, Johannesburg; ${ }^{2}$ Division of Nephrology, Charlotte Maxeke Johannesburg Academic Hospital
}

\begin{abstract}
Background: No consensus exists on the treatment of LPABMR. Lymphocyte depletion may produce sustained alloantibody reduction by indirect plasma cell depletion. We analysed response to Rituximab (RTX) and ATG in the CMJAH LPABMR cohort.

Methods: Analysis of clinical remission defined by stabilisation of graft function in response to plasmapheresis +IVIg followed by RTX or ATG was undertaken ( $n=34)$ using Cox-Mantel survival analysis and Cox proportional hazards. Factors influencing ATG/RTX prescription were analysed by logistic regression.
\end{abstract}

Results: RTX was administered in 23 cases (67.6\%) and ATG in 11 (32.3\%). No significant differences were found in baseline alloantibody, graft age, or i-score/IFTA grade categories; creatinine at diagnosis was higher in the ATG cohort $(358 \mathrm{mmol} / \mathrm{L}$ vs $106.3 \mathrm{mmol} / \mathrm{L}, \mathrm{p}=0.03)$. Creatinine was dependent on i-score $\left(b=0.429, \mathrm{SE} \mathrm{b}^{2}=0.156, \mathrm{p}=0.008\right)$ but not on IFTA grade or cg-score. ATG/RTX choice was dependent on i-score ( $\mathrm{i} \geq 2 \mathrm{~b}=1.551, \mathrm{SE}^{2}=0.772$, Wald's $\left.\mathrm{c}^{2}=4.030, \mathrm{p}=0.044\right)$ but not on creatinine, IFTA grade, cg-score, presence of mixed rejection, or antibody specificity/MFI. Preferential use of ATG for $\mathrm{i} \geq 2$ thus accounted for higher baseline creatinine in this group.

Poorer survival was observed for ATG vs RTX ( $F=2.28, p=0.023)$; since $\mathrm{i} \geq 2$ was a significant risk for failure of remission ( $\mathrm{HR}=2.64, \mathrm{p}=0.021)$, this was hypothesised be due to the preferential use of ATG for $i \geq 2$.

To test this, survival analysis stratified for $\mathrm{i} \geq 2$ was undertaken. Poorer survival was observed for ATG vs RTX (F=1.306, $\mathrm{p}=0.191)$ with a possible harm signal detected $(\mathrm{HR}=3.25, \mathrm{p}=0.231)$.

Conclusion: RTX appears superior to ATG for LPABMR. ATG may accelerate graft loss particularly in the context of an i-score $\geq 2$. 


\title{
ABSTRACTS OF THE SOUTH AFRICAN RENAL SOCIETY (SARS) 2016 CONGRESS (CAPE TOWN 9-11 SEPTEMBER 2016) \\ POSTER PRESENTATION ABSTRACTS
}

\section{P13 - Failure to Launch: Exclusion from Living Kidney Donation at Charlotte Maxeke Johannesburg Academic Hospital (1983-2015)}

\author{
C Dayal ${ }^{1}$, N Diana ${ }^{1,2}$, M Davies ${ }^{1,2}$, AM Meyers ${ }^{3}$, G Paget ${ }^{1,2}$ \\ ${ }^{1}$ Department of Internal Medicine, Faculty of Health Sciences, University of Witwatersrand, South Africa; ${ }^{2}$ Department of \\ Internal Medicine, Division of Nephrology, Faculty of Health Sciences, University of Witwatersrand, South Africa; ${ }^{3}$ Emeritus \\ Professor of Medicine in the Faculty of Health Sciences, University of Witwatersrand, South Africa and Chairman of the \\ National Kidney Foundation
}

\begin{abstract}
Background: Living donation offers the potential to significantly expand kidney transplantation with superior quality grafts which are more likely to have higher rates of HLA matching, in turn improving long-term allograft survival. Nevertheless, rates of living donation in many centres are low. We analysed outcomes of evaluation of potential living donors (PLDs) at CMJAH to characterise reasons for exclusion from donation.

Methods: We retrospectively reviewed 1,208 PLDs evaluated at our Living Donor Clinic over a 32year period. Of the total cohort, 298 ultimately donated a kidney, resulting in 910 Failed Living Donors (FLDs). We evaluated donor demographics, donation patterns and reasons for non-donation in the FLD group.

Results: Of 910 FLDs, $522(57.4 \%)$ were female. The majority were of black African origin (474, $52.1 \%$ ) and Caucasian $(358,39.3 \%)$. The greatest number of FLDs were aged between 30 and 39 years $(315,34.6 \%)$. With respect to donor patterns $722(79.3 \%)$ FLDs were potential related living donors, $180(19.8 \%)$ were potential directed non-related living donors, only $8(0.9 \%)$ were potential non-directed non-related living donors. Most FLDs (82\%) aged between 22 and 49 years planned to donate sideways to recipients of a similar generational group. Outcome of PLD evaluation varied significantly by race $(\mathrm{p}<0.001)$, with only a third of black PLDs being accepted for donation. Black versus Caucasian PLDs were more likely to fail work-up ( $77 \%$ vs $71 \%$; $=0.04)$ and be excluded for medical reasons $(44 \%$ vs $35 \%$; $<<0.001)$. Leading medical exclusions included hypertension, HIV and obesity, while 228 (25\%) of the FLDs were medically accepted for donation but did not donate a kidney due to a variety of reasons.
\end{abstract}

Conclusion: There is a significant exclusion rate for PLDs. Black PLDs are more likely to be excluded than Caucasian counterparts due to significant co-morbidity. 


\title{
ABSTRACTS OF THE SOUTH AFRICAN RENAL SOCIETY (SARS) 2016 CONGRESS (CAPE TOWN 9-11 SEPTEMBER 2016) \\ POSTER PRESENTATION ABSTRACTS
}

\section{P14 - Metformin Associated Lactic Acidosis: A report of two cases following Intentional and Unintentional Overdose}

\author{
B Mbena ${ }^{1}$, E Effa $^{1,2}$, B Rayner ${ }^{1}$ \\ ${ }^{1}$ University of Cape Town/Groote Schuur Hospital, Cape Town, South Africa; ${ }^{2}$ University of Calabar, Calabar, Nigeria
}

\begin{abstract}
Background: Metformin associated lactic acidosis is a life threatening condition that is increasingly being encountered. We report two cases referred to our medical emergency unit in severe lactic acidosis following intentional and unintentional overdose respectively.

Methods: Case records review.

Results: Case 1: Miss BM, a 33-year-old HIV-positive female who was stable on ARVs and presented with a history of ingesting an unknown amount of metformin, enalapril and lansoprazole. She had altered mental status, kussmaul's breathing and severe lactic acidosis, and later developed hypoglycaemia and hypovolaemic shock requiring inotropic support. Her arterial blood gas results were as follows: $\mathrm{pH} 7.024, \mathrm{pCO}_{2}$ of $1.41 \mathrm{kpa}, \mathrm{pO}_{2} 17.4 \mathrm{kpa}, \mathrm{K}^{+} 4.2 \mathrm{mmol} / \mathrm{L}, \mathrm{Na} 141 \mathrm{mmol} / \mathrm{L}$, Chloride $110 \mathrm{mmol} / \mathrm{L}$, Glucose $7.5 \mathrm{mmol} / \mathrm{L}$, Bicarbonate $2.6 \mathrm{mmo} / \mathrm{L}$, base excess of -29.2 and a lactate level $>15$. Assays for paracetamol levels were within normal limits. Her lactic acidosis worsened despite treatment with fluids, ionotropes, sodium bicarbonate infusion and intermittent hemodialysis. She demised within 48 hours of presentation.

Case 2: Mrs VD, a 62-year-old lady newly diagnosed with type 2 diabetes following repeated plasma glucose levels of $28 \mathrm{mmol} / 1$ and above. She was started on metformin by her GP following which she presented a week later with nausea, persistent vomiting, anuria, hypoglycaemia (Blood sugar $2.5 \mathrm{mmol} / \mathrm{l}$ ) and metabolic acidosis with a $\mathrm{pH}$ of $6.88, \mathrm{HCO}_{3}$ of $6.1 \mathrm{mmol} / \mathrm{L}, \mathrm{pO}_{2}$ of $15.9 \mathrm{kpa}$ and a lactate of 29 with a base excess of -25.2. Her urine ketones were negative. Her hemoglobin was $15 \mathrm{~g} / \mathrm{dl}$, she had a leucocytosis of 22,540 cells $/ \mathrm{mm}^{3}$ and was in renal failure with a creatinine of $884 \mu \mathrm{mol} / \mathrm{l}$. She was on ventilatory support, had intravenous sodium bicarbonate, ceftriaxone and pantoprazole as well as continuous veno-venous hemodiafiltration. She demised within 48 hours of admission.
\end{abstract}

Conclusion: Intentional overdose with metformin should be suspected in non-diabetics with lactic acidosis. Metformin is contraindicated in diabetics with CKD 4 and 5, and should be used with caution in patients with CKD 3b. 


\title{
ABSTRACTS OF THE SOUTH AFRICAN RENAL SOCIETY (SARS) 2016 CONGRESS (CAPE TOWN 9-11 SEPTEMBER 2016)
}

\section{POSTER PRESENTATION ABSTRACTS}

\section{P15 - Prevalence of Chronic Kidney Disease (CKD) In HIV Populations: A Systematic Review and Meta-analysis}

\author{
UE Ekrikpo ${ }^{1}$, EE Effa ${ }^{2}$, AP Kengne ${ }^{3}$, IG Okpechi ${ }^{1}$ \\ ${ }^{1}$ University of Cape Town, South Africa; ${ }^{2}$ University of Calabar, Nigeria; ${ }^{3}$ Medical Research Council, South Africa
}

\begin{abstract}
Background: With the advent of antiretroviral therapy, HIV patients now live longer and are prone to chronic non-communicable diseases including CKD. We undertook a systematic review and metaanalysis to determine the global prevalence of CKD in adult HIV populations, and assess the variation by region and major HIV/AIDS predictive characteristics.

Methods: We searched multiple databases including Pubmed-Medline, Web of Science, EBSCO, Cochrane Library, ScieLO and AJOL from 1982 to 2016, for published and unpublished articles on CKD in people with HIV, using relevant key words and MeSH terms. Manual search of reference list of eligible articles and contact with relevant experts was also done. The pooled prevalence of CKD overall and by subgroup was computed using the random effects model meta-analysis and meta-regression used to identify study-level factors associated with variations in CKD prevalence. The protocol was registered with PROSPERO (CRD42016036246).

Results: Of the 1,959 entries identified via searches, 41 met the inclusion criteria and were included in the final selection. CKD across these studies was diagnosed using MDRD-based eGFR ( $\mathrm{n}=41$ studies). These studies comprised 155,044 HIV-positive patients from across the WHO regions. The pooled prevalence of CKD $\left(\mathrm{eGFR}<60 \mathrm{ml} / \mathrm{min} / 1.73 \mathrm{~m}^{2}\right)$ was $6.5 \%(95 \%$ CI $5.8-7.3 \%)$ overall; $9.5 \%$ (7.6$11.4 \%$ ) in sub-Saharan Africa, 3.1\% (2.3-4.0) in Europe, 6.0\% (4.6-7.4\%) in North America, 6.5\% (1.411.5\%) in South America; 4.1\% (2.7-5.5\%) in Western Pacific; $\mathrm{p}<0.001$ There was always evidence of heterogeneity (all $\mathrm{p}<0.001$ ), partly explained by regional differences in meta-regression analyses. There was no evidence of publication bias.
\end{abstract}

Conclusion: There is a high prevalence of CKD amongst the HIV population globally, especially in Sub-Saharan Africa (SSA). Efforts to reduce disease burden through kidney disease screening amongst HIV-positive patients and treatment to retard progression should be implemented. There is need for additional research to identify further disease risk factors in SSA. 


\title{
ABSTRACTS OF THE SOUTH AFRICAN RENAL SOCIETY (SARS) 2016 CONGRESS (CAPE TOWN 9-11 SEPTEMBER 2016) \\ POSTER PRESENTATION ABSTRACTS
}

\section{P16 - Optimising Aspects that Facilitate Skill Acquisition in Private Dialysis Units}

\author{
Claire Fourie \\ Nelson Mandela Metropolitan University, National Renal Care
}

\begin{abstract}
Background: Nephrology nursing requires a specific set of clinical skills and knowledge. A training intervention for skills transfer and acquisition based on experiential learning was implemented. Experiential learning depends on many factors that could either hinder or facilitate skill acquisition. Aims: This study aimed to explore and describe the aspects that facilitate or hinder skill acquisition and to develop guidelines to optimise skill acquisition during experiential learning. The study followed a quantitative, descriptive, exploratory, contextual, survey design.

Results: Findings indicated that overall the participants felt the aspects that either hinder or facilitate skill acquisition were facilitating skill acquisition. Amongst the four sub-sections, practice environment was identified as the sub-section with the lowest overall mean score (3.8) and less experienced professional nurse as the sub-section with the highest overall mean score (4.4). Findings further indicated that both clinical (4.0) and management skills (3.6) were transferred. Specific aspects highlighted that needed to be addressed were: more hands-on training sessions, improved availability of resources like internet access, more opportunity to experience situations and practice what has been learnt, more peer and group discussions, a more structured skill acquisition programme to be implemented, and time for feedback and reflection.
\end{abstract}

Conclusion: Three principle guidelines were developed. Firstly, strategic management to facilitate skills acquisition within the organisation, focusing on responsibility, workload, time allocation, skills mix, structured training programme and learning culture. Secondly, implementation of the teaching and learning processes to facilitate skills acquisition, focusing on equipping the responsible persons with teaching and learning strategies. And thirdly, maximising effectiveness of skill acquisition amongst the professional nurses through focusing on transferring of specific skills, both clinical and non-clinical. 


\title{
ABSTRACTS OF THE SOUTH AFRICAN RENAL SOCIETY (SARS) 2016 CONGRESS (CAPE TOWN 9-11 SEPTEMBER 2016) \\ POSTER PRESENTATION ABSTRACTS
}

\section{P17 - Lived Experiences of Hemodialysis Patients with Erectile Dysfunction: A Phenomenological Study}

\author{
Tilly Govender ${ }^{1}$ \\ ${ }^{1}$ National Renal Care, South Africa
}

\begin{abstract}
Introduction: Erectile dysfunction is a common phenomenon experienced by patients on a hemodialysis programme. Erectile dysfunction affects all areas of human functioning - the physical, psychological and social dimensions. The aim of this study was to generate an in-depth understanding of the lived experiences of patients with erectile dysfunction who were on a hemodialysis programme in three National Renal Care units in KwaZulu-Natal, and thereafter to propose recommendations for the professional nurse practitioner to facilitate the mental health of patients in the context of this study.

Methods: A phenomenological research design that was qualitative, explorative and contextual in nature was utilised. The data collection methods utilised were phenomenological interviews, naïve sketches and field notes. Purposive sampling guided by data saturation, was used with nine participants in the study. Results: The findings revealed that the participants' lived experiences of erectile dysfunction reflected losses in the psychological (loss of identity, loss of self-worth, loss of sexual fulfilment), physical (loss in erectile functioning), and social (loss in sharing and communicating experiences of erectile dysfunction, loss of emotional closeness in the relationship) dimensions that seemingly influenced their mental health negatively. Based on the findings and the literature review, recommendations were proposed. The recommendations then served as a frame of reference to enable the professional nurse practitioner to render holistic nursing care.
\end{abstract}

Conclusion: From the findings of this study it became evident that the patients who were experiencing erectile dysfunction and who were on a hemodialysis programme endured multiple losses in the psychological, physical and social dimensions. It was thus found that the phenomenon of erectile dysfunction negatively impacted on the patients' mental health. 


\title{
ABSTRACTS OF THE SOUTH AFRICAN RENAL SOCIETY (SARS) 2016 CONGRESS (CAPE TOWN 9-11 SEPTEMBER 2016)
}

\section{POSTER PRESENTATION ABSTRACTS}

\section{P18 - Transforming Growth Factor- $\beta$ Isoforms Protect against Endotoxaemia Related Atherosclerosis in Chronic Kidney Disease Patients}

\author{
Muzamil Hassan ${ }^{1,5}$, Raquel Duarte ${ }^{2}$, Therese Dix-Peek ${ }^{2}$, Caroline Dickens ${ }^{2}$, Sagren Naidoo ${ }^{1}$, Ahmed Vachiat ${ }^{3}$, \\ Sacha Grinter ${ }^{3}$, Pravin Manga ${ }^{3}$ and Saraladevi Naicker ${ }^{4}$ \\ ${ }^{1}$ Divisions of Nephrology, Department of Internal Medicine, Faculty of Health Sciences, University of the Witwatersrand, \\ South Africa; ${ }^{2}$ Internal Medicine Research Laboratory, Department of Internal Medicine, Faculty of Health Sciences, University \\ of the Witwatersrand, South Africa; ${ }^{3}$ Division of Cardiology, Department of Internal Medicine, Faculty of Health Sciences, \\ University of the Witwatersrand, South Africa; ${ }^{4}$ Department of Internal Medicine, Faculty of Health Sciences, University of \\ the Witwatersrand, South Africa; ${ }^{5}$ Renal Unit, Department of Medicine, Obafemi Awolowo University Teaching Hospital \\ Complex, Ile-Ife, Osun State, Nigeria
}

\begin{abstract}
Background: Endotoxin, a potential source of inflammation, is closely linked to several complications of $\mathrm{CKD}$, driving chronic inflammation, oxidative stress and atherosclerosis. Transforming growth factor- $\beta 1$ (TGF- $\beta 1$ ), a multifunctional inflammatory cytokine inhibits the development of atherosclerosis in CKD patients. We assessed the potential role of endotoxaemia for susceptibility to atherosclerosis in CKD patients and evaluated serum levels of three TGF- $\beta$ isoforms to assess the impact of TGF- $\beta$ on the development of atherosclerosis, and determine if any association exists between polymorphism in the TGF- $\beta 1$ gene and atherosclerosis in CKD patients.

Methods: We studied $120 \mathrm{CKD}$ patients comprising hemodialysis, peritoneal dialysis and CKD stage 3 patients (40 in each group) and 40 healthy controls. Serum endotoxin and TGF- $\beta 1$ levels were measured. Polymorphisms in the coding region of TGF- $\beta 1$ genes $(+869 \mathrm{~T} \rightarrow \mathrm{C}$ at codon 10 and +915 $\mathrm{G} \rightarrow \mathrm{C}$ at codon 25) were genotyped. Carotid intima-media thickness (CIMT) was assessed by B-mode ultrasonography.

Results: Overall, the risk of atherosclerosis was associated with serum levels of endotoxins in CKD patients (OR: 2.34; 95\% Cl: 1.26-4.35, $\mathrm{p}=0.007$ ), with excess risk confined to the group with high endotoxin levels. Serum TGF- $\beta$ isoforms were present in lower concentrations in the spectrum of CKD patients compared to the controls. Serum TGF- $\beta$ concentrations were significantly reduced in the patients with atherosclerosis compared to patients without atherosclerosis. Serum TGF- $\beta$ isoforms had an inverse relationship with CIMT (TGF- $\beta 1$ : $\mathrm{r}=-0.562$, $\mathrm{p}<0.001$; TGF- $\beta 2$ : $\mathrm{r}=-0.477, \mathrm{p}<0.001$; TGF- $\beta 3$ : $\mathrm{r}=-0.442, \mathrm{p}<0.001)$. However, no association was found between the TGF- $\beta 1$ gene polymorphisms and atherosclerosis risk.
\end{abstract}


Conclusion: The findings suggest that the degree of circulating endotoxaemia was related to the severity of atherosclerosis, with protection afforded by serum TGF- $\beta$ isoforms levels. These results - which must be confirmed by a larger study - did not provide evidence of an association between the TGF- $\beta 1$ gene polymorphisms and atherosclerosis in South African CKD patients. 


\title{
ABSTRACTS OF THE SOUTH AFRICAN RENAL SOCIETY (SARS) 2016 CONGRESS (CAPE TOWN 9-11 SEPTEMBER 2016)
}

\section{POSTER PRESENTATION ABSTRACTS}

\section{P19 - The Influence of Polymorphisms in the Interleukin-6 (IL-6) Gene on Serum IL-6 Levels and Association with Atherosclerosis in South African Chronic Kidney Disease Patients}

\author{
Muzamil Hassan ${ }^{1,5}$, Raquel Duarte ${ }^{2}$, Caroline Dickens², Therese Dix-Peek², Sagren Naidoo ${ }^{1}$, Ahmed Vachiat ${ }^{3}$, \\ Sacha Grinter ${ }^{3}$, Pravin Manga ${ }^{3}$ and Saraladevi Naicker ${ }^{4}$ \\ ${ }^{1}$ Divisions of Nephrology, Department of Internal Medicine, Faculty of Health Sciences, University of the Witwatersrand, \\ South Africa; ${ }^{2}$ Internal Medicine Research Laboratory, Department of Internal Medicine, Faculty of Health Sciences, University \\ of the Witwatersrand, South Africa; ${ }^{3}$ Division of Cardiology, Department of Internal Medicine, Faculty of Health Sciences, \\ University of the Witwatersrand, South Africa; ${ }^{4}$ Department of Internal Medicine, Faculty of Health Sciences, University of \\ the Witwatersrand, South Africa; ${ }^{5}$ Renal Unit, Department of Medicine, Obafemi Awolowo University Teaching Hospital \\ Complex, Ile-Ife, Osun State, Nigeria
}

\begin{abstract}
Background: Inflammation is a major risk factor for atherosclerosis in the general population. Genetic polymorphisms in the inflammatory cytokine genes have been associated with atherosclerosis. Because inflammatory cytokines are markedly elevated in CKD patients, it was hypothesised that genotypic variations in inflammatory cytokine genes are a cause of systemic inflammatory states and atherosclerosis in South African CKD patients.

Methods: A total of 120 CKD patients and 40 healthy controls were included. Serum interleukin-6 (IL-6) and C-reactive protein (CRP) levels were measured using Luminex Performance Assay multiplex kits. Functional polymorphisms in the IL-6, TNF- $\alpha$, IL-10 and IFN- $\gamma$ genes were genotyped using polymerase chain reaction-sequence specific primer (PCR-SSP) methods with a cytokine genotyping tray. Carotid intima-media thickness (CIMT) and the presence of plaque were assessed by B-mode ultrasonography.

Results: Serum IL-6 and CRP levels were increased in patients with CKD compared with healthy controls $(\mathrm{p}<0.001)$. In CKD patients, serum IL-6 above the median value was associated with carotid plaque (OR: 2.11; 95\% CI:1.74-2.57, $\mathrm{p}=0.004$ ), with excess risk confined to the group with high IL-6 levels. In the subgroup analyses, significant associations were found between IL-6 gene and atherosclerosis in the $\mathrm{CKD}$ group (for $\mathrm{G} / \mathrm{G}$ genotype: $\mathrm{OR}=1.21$, $95 \% \mathrm{CI}=1.05-1.39$, $\mathrm{p}=0.012$; for $\mathrm{GG}+\mathrm{GC}$ vs $\mathrm{CC}: \mathrm{OR}=1.14,95 \% \mathrm{CI}=1.02-1.28, \mathrm{p}=0.035)$. Patients with $\mathrm{GG}+\mathrm{GC}$ genotype of the IL6 gene polymorphism had higher levels of IL-6 than those with CC genotype $(\mathrm{p}=0.029)$. However, no significant association was found between the TNF- $\alpha$, IL-10 and IFN- $\gamma$ gene polymorphisms and markers of atherosclerosis.
\end{abstract}


Conclusion: In South African CKD patients, high serum IL-6 levels are associated with the IL-6 gene promoter polymorphism and markers of atherosclerosis. The relationship between atherosclerosis and $-174 \mathrm{G} / \mathrm{C}$ polymorphism in the IL-6 gene suggests that IL- 6 may be a potential pro-inflammatory mediator of atherosclerosis in CKD patients. 


\title{
ABSTRACTS OF THE SOUTH AFRICAN RENAL SOCIETY (SARS) 2016 CONGRESS (CAPE TOWN 9-11 SEPTEMBER 2016)
}

\section{POSTER PRESENTATION ABSTRACTS}

\section{P20 - Clinico-pathological Features of the Re-Biopsy in Patients with Lupus Nephritis at Groote Schuur Hospital, Cape Town}

\author{
S Kajawo ${ }^{1}$, F Botha ${ }^{2}$, IG Okpechi ${ }^{1}$ \\ ${ }^{1}$ Division of Nephrology and Hypertension, University of Cape Town; ${ }^{2}$ Division of Anatomical Pathology, University of Cape \\ Town
}

\begin{abstract}
Background: Repeat biopsies are often performed for patients with lupus nephritis (LN) to guide treatment or to establish disease chronicity. The aim of this study is to provide a report on the clinicopathological features of repeat renal biopsies in patients with LN treated at Groote Schuur Hospital, Cape Town.

Methods: Ethical approval was granted by the Ethics Committee of the University of Cape Town. All patients with biopsy proven LN who had a repeat biopsy between January 2003 and December 2014 were recruited. Electronic, paper records and histological slides were retrieved and reviewed. The data was analysed using SPSS version 22 for Windows.

Results: A total of 44 patients had at least two biopsies done during the study period. The average age at first biopsy was 25.7 (13.7-58.3) years, and 28.4 (14.4-60.4) years at second biopsy. Most patients were female $(81.8 \%)$, with elevated proteinuria being the main indication at first and second biopsy $(43.2 \%$ and $29.5 \%)$. There was significant worsening eGFR $(p=0.001)$ and proteinuria $(p=0.019)$ between both biopsies suggesting disease progression. At the second biopsy, 27.3\% had the same class of LN while $72.7 \%$ had switched class. Of the patients with proliferative LN at reference biopsy (40.9\%), 14/18 $(77.8 \%)$ remained as proliferative LN. There was significant increase in chronicity score at the second biopsy from 1 to 3.5 ( $\mathrm{p}<0.0001)$. Surprisingly, the activity index was also significantly higher at the time of the second biopsy from 3.9 to $7(p=0.005)$. Most patients $(17 / 26,65.4 \%)$ with a non-proliferative LN transformed into a proliferative class. The second biopsy prompted escalation of therapy in $72 \%$, reduction/discontinuation of treatment in $12 \%$ dose reduction, and no treatment change in $15 \%$.
\end{abstract}

Conclusion: This study highlights the importance of a repeat renal biopsy in patients with LN and suggests earlier intervention to halt disease progression. 


\title{
ABSTRACTS OF THE SOUTH AFRICAN RENAL SOCIETY (SARS) 2016 CONGRESS (CAPE TOWN 9-11 SEPTEMBER 2016) \\ POSTER PRESENTATION ABSTRACTS
}

\section{P21 - Improving Rates of Vascular Access at Dialysis Start and Reducing Morbidity and Mortality - The St George Hospital Experience in Australia}

\author{
Y Martinez-Smith ${ }^{1}$, C Meek ${ }^{1}$, IJ Katz ${ }^{1}$ \\ ${ }^{1}$ Department of Renal Medicine, The St George Hospital and University of New South Wales, Sydney, Australia
}

\begin{abstract}
Background: The preferred hemodialysis (HD) access is a native arteriovenous fistula (AVF). Starting HD with a working functional fistula reduces morbidity and improves survival. In 2003, following poor numbers starting with an AVF and high infection rates, a unique Vascular Access Nurse (VAN) Consultant service was established. The aim of this audit is to assess its progress and impact over the years since implementation.

Methods: All patients nearing ESKD were referred to the VAN clinic. The VAN evaluated and planned referrals to vascular surgeons, including monitoring the access from creation to the start of dialysis. After dialysis was commenced monitoring continued to ensure patency and a low level of fistula and permanent catheter (Vascath) infection were maintained. Outcomes were benchmarked against national ANZDATA criteria with KPIs $>38 \%$ for commencement with AVF; $>78 \%$ prevalent AVF and $<10 \%$ Vascaths.

Results: From 155 HD patients and 34 new patients in 2015, a total of 58\% commenced dialysis with a mature access - AVF (46\%) and AVG (12\%). Of prevalent patients, $90 \%$ had an AVF/AVG and 3\% a Vascath. At first HD, 19 (63\%) had a mature access, compared to ANZDATA benchmark of 50\%. Average time from referral to access creation was 41 days. Average time to cannulation was 6.5 months. Thrombosis rates were 1.7 episodes/pt-year (aim <0.25). AVG/SVG $=0.8$ episodes/pt-year (aim $<0.5)$. There was 1 Vascath and nil exit-site infections for 85 catheters in situ. Long-term patency rates: AVF at 5 years (85\%), at 10 years (75\%); AVG at 1 year (62\%), 2 years (54\%), 3 years (54\%); Flexine graft at $1-3$ years $(80 \%)$.
\end{abstract}

Conclusion: Developing a VAN service has significantly improved native AVF rates and outcomes. Our service is achieving KPIs above national and international benchmark targets. A VAN driven service is a very attractive model to improve outcomes for HD patients. 


\title{
ABSTRACTS OF THE SOUTH AFRICAN RENAL SOCIETY (SARS) 2016 CONGRESS (CAPE TOWN 9-11 SEPTEMBER 2016)
}

\section{POSTER PRESENTATION ABSTRACTS}

\section{P22 - Iconnect Care CKD: A Web-based Chronic Kidney Disease Programme}

IJ Katz ${ }^{1}$, V Raghunath ${ }^{1}$, S Pirabhahar ${ }^{1}$, P Williamson ${ }^{1}$, J Kelly ${ }^{1}$, A O’Sullivan², G Youssef ${ }^{3}$, C Lane $^{1}$, F Brennan ${ }^{1}$, E Josland ${ }^{1}, \mathrm{~S}$ Tranter $^{1}, \mathrm{M}$ Brown ${ }^{1}$

${ }^{1}$ Department of Renal Medicine; ${ }^{2}$ Department of Endocrinology; ${ }^{3}$ Department of Cardiology, The St George Hospital and University of New South Wales, Sydney, Australia

\begin{abstract}
Background: Specialists are often overwhelmed with low risk (LR) chronic kidney disease (CKD) patients (eGFR $>30 \mathrm{mls} / \mathrm{min}$; albuminuria $<30 \mathrm{mg} / \mathrm{mmol} \mathrm{Cr}$ ), who can be managed safely in the primary care (PC). Opportunistic screening of high risk (HR) CKD patients and follow-up in PC is the most sustainable option, decentralising management and optimising workload. iConnect Care CKD provided a 'virtual consultation' (VC) instead of face-to-face (F2F) follow-up. It evolved from a programme developed in Soweto, South Africa. The aims of this study were to assess efficacy and safety of a webbased VC model of care.

Methods: A total of 70 patients were recruited and followed for one year. The HR patients (eGFR< $30 \mathrm{ml} / \mathrm{min} / 1.73 \mathrm{~m}^{2}+/$ - albuminuria $>30 \mathrm{mg} / \mathrm{mmol} / \mathrm{L}$ ) were randomised to VC follow-up or F2F. Data was collected and progress monitored every six months by a clinical nurse specialist. A specialist team providing VCs comprised a nephrologist, endocrinologist, cardiologist and palliative care physician.

Results: A total of $61(87 \%)$ patients were consulted with $9(13 \%)$ of these being HR. At 12 months there was no difference in progress or outcomes in HR VC versus F2F groups nor in LR patients followed by CNC or the GP. A total of 9 people died; 7 in the HR and 2 in LR group, and only 1 from ESKD. All patients were successfully followed. The programme software and IT integration was challenging, but GPs and patients still reported a high level of satisfaction with it. VC patients were seen within a week and a second specialist opinion within another two weeks.
\end{abstract}

Conclusion: The programme allowed safe, quick and efficient consultation from multiple specialists. It expedited time to review and reduced F2F referral. There were logistical issues with system integration impacting uptake. VC has a role to play in future patient care and ongoing evaluation should occur to determine its exact role in chronic disease management. 


\title{
ABSTRACTS OF THE SOUTH AFRICAN RENAL SOCIETY (SARS) 2016 CONGRESS (CAPE TOWN 9-11 SEPTEMBER 2016)
}

\section{POSTER PRESENTATION ABSTRACTS}

\section{P23 - Symptom Control Management for Patients with Renal Disease - The St George and Sutherland Hospitals Renal Supportive Care Service}

\author{
IJ Katz ${ }^{1}$, E Josland, A Hoffman, H Burgess, A Smyth, J Stevenson, M Brown and F Brennan ${ }^{1,2}$ \\ ${ }^{1}$ Department of Renal Medicine; ' $P a l l i a t i v e ~ C a r e$, The St George Hospital and University of New South Wales, Sydney,
} Australia

\begin{abstract}
Background: Worldwide not all patients are suitable for dialysis. In some developed countries Renal Supportive Care (RSC) clinics are becoming mainstream in nephrology services. In developing countries where the issue is impacted by service restrictions and exclusion due to resource limitations, it is argued that such services provide holistic care and emphasise the quality of life. The aim was to present data on the symptom burden of patients seen by the RSC service at The St George and Sutherland Hospitals.

Methods: An audit of RSC services occurs annually. RSC comprises a specialist, clinical nurse consultants, social worker and dietician. The three main categories of services are: i) Conservative care support. ii) Dialysis or pre-dialysis symptom control. iii) Dialysis withdrawal management. Symptom surveys are completed by patients at each visit using the IPOS - Renal including demographic data of age, sex and co-morbidity.

Results: RSC consultations occurred at multiple sites of service delivery; outpatient clinics at The St George (264) and Sutherland (81) Hospitals, in hospital (692), home visits (49), phone consultations (136) and while on dialysis (405). Demographics of patients on conservative 'non-dialysis' pathway: Age 83 years vs dialysis 70 years; diabetes 47\% vs 51\%; dementia 13\% vs 4\%; and two or more comorbidities $52 \%$ vs $49 \%$. Age range was $17-99$ years. A total of $61 \%$ had reduction in symptom scores at follow-up after treatment. Pain, lack of energy, poor mobility, itch and difficulty sleeping were the most prevalent symptoms.
\end{abstract}

Conclusion: The service is now a key component of care for patients with advanced renal disease. It has addressed gaps in care for ESKD patients with being managed conservatively and on renal replacement therapies with persistent symptoms. As RSC services are rolling out around Australia there is an argument to the value of providing such services to countries with less resources. As this is a nurse-led service it remains economically attractive. 


\title{
ABSTRACTS OF THE SOUTH AFRICAN RENAL SOCIETY (SARS) 2016 CONGRESS (CAPE TOWN 9-11 SEPTEMBER 2016)
}

\section{POSTER PRESENTATION ABSTRACTS}

\section{P24 - Chronic Interstitial Nephritis at Protocol Biopsy: A Harbinger of Rejection?}

\author{
F Khan ${ }^{1,2}$, P Lusu ${ }^{1}$, M Davies ${ }^{1,3}$, S Saffer ${ }^{1}$, G Paget ${ }^{1,3}$ \\ ${ }^{1}$ University of the Witwatersrand, Johannesburg; ${ }^{2}$ Division of Nephrology, Department of Internal Medicine, Helen Joseph \\ Hospital; ${ }^{3}$ Division of Nephrology, Department of Internal Medicine, Charlotte Maxeke Johannesburg Academic Hospital
}

\begin{abstract}
Introduction: Immunological mechanisms, particularly antibody-mediated rejection (ABMR), are increasingly recognised as the major barrier to long-term renal allograft survival. Late-period rejection is more resistant to therapy, possibly due to a highly efficient and specific alloimmune response. We hypothesised that 'idiopathic' chronic interstitial nephritis (CIN) at protocol biopsy may represent an early stage in recipient immune system - allograft engagement and thus an opportunity to prevent later rejection.
\end{abstract}

Methods: We retrospectively reviewed a protocol-biopsy cohort $(\mathrm{n}=89)$ in order to evaluate the effect of subclinical CIN on allograft survival. The Log-rank test and Cox proportional hazards method were used to evaluate survival; continuous variables were compared using the Mann-Whitney $\mathrm{U}$ test, and categorical variables using the Fisher Exact test/Pearson $c^{2}$ test.

Results: CIN was a frequent finding at protocol biopsy, and the prevalence of CIN increased between biopsy intervals (44.4\% at three-month and $55.6 \%$ at 12 -month, $\mathrm{p}=0.192)$. The presence of CIN at protocol biopsy was associated with poorer allograft lifespan (Log rank=1.862, $\mathrm{p}=0.062$, Cox proportional HR 3.44, $\mathrm{p}=0.094$; figure 1) and with reduced rejection-free allograft survival after biopsy (Log rank 2.147, $\mathrm{p}=0.032$, Cox proportional HR 3.926, $\mathrm{p}=0.071$ ). The dominant cause of graft loss in patients from this cohort undergoing late-period for-cause biopsy $(\mathrm{n}=47)$ was rejection $(75 \%$ of cases of graft loss, $\mathrm{p}=0.052)$. A non-significant trend toward increased frequency of all rejection categories and IFTA/CAN was observed at for-cause biopsy in those patients with CIN at protocol biopsy $(p=0.285)$.

Conclusion: CIN at protocol biopsy portends poorer allograft outcomes and is associated with late-period rejection. CIN at protocol biopsy may represent an intervention target for prevention of late-period rejection. 


\title{
ABSTRACTS OF THE SOUTH AFRICAN RENAL SOCIETY (SARS) 2016 CONGRESS (CAPE TOWN 9-11 SEPTEMBER 2016) \\ POSTER PRESENTATION ABSTRACTS
}

\section{P25 - The Prevalence of Secondary Hyperparathyroidism in Chronic Renal Disease Patients}

\author{
N Kistnasamy \\ National Renal Care, Durban University of Technology
}

\begin{abstract}
Introduction: Managing hyperphosphataemia and limiting the intake of phosphate and reducing calcium load together with the consequences or hyperparathyroidism are a great challenge in dialysis.

Objective: To determine the prevalence of secondary hyperparathyroidism among hemodialysis patients in an uMhlanga dialysis unit, KwaZulu-Natal.

Methods: A quantitative research, 37 chronic hemodialysis (HD) patients undergoing HD three times a week participated in the study over a two-year period, July 2011 to July 2013. The research study included the measurements of calcium, phosphate and parathyroid hormone (PTH) as well as residual renal function (RRF).

Results: A sample size of $\mathrm{n}=37$ patients was included, 30 patients were on hemodialysis for longer than four years and 7 patients were on HD for at least one year. All the patients underwent HD three times a week for four hours. The results of both groups were compared. Blood testing was done six monthly and three variables were compared i.e. serum phosphate, calcium and parathyroid hormone. A total of $78 \%$ of patients on HD longer than three years had PTH levels above the normal parameter of $150 \mathrm{pg} / \mathrm{ml}$ which increased yearly as phosphate levels increased. $22 \%$ of pts on HD less than a year had PTH levels below the normal parameter. This gives an indication that PTH levels increase as time on HD increases.
\end{abstract}

Conclusion: A significant difference was identified in the blood results. This indicated that patients on HD longer are more prone to develop CKD-MBD. BMD in chronic HD is a common complication which may impact on the quality of life of the patient. Despite advances in hemodialysis treatment facilities and the use of calcium based phosphate binders, the incidence of secondary hyperparathyroidism remains high. Good preventative measures and protocols are still needed to tackle this issue in chronic HD patients. 


\title{
ABSTRACTS OF THE SOUTH AFRICAN RENAL SOCIETY (SARS) 2016 CONGRESS (CAPE TOWN 9-11 SEPTEMBER 2016) \\ POSTER PRESENTATION ABSTRACTS
}

\section{P26 - The Relationship between Dialysis Adequacy and Nutrition in Hemodialysis Patients}

\author{
MJ Mahambane: LT Hazelhurst ${ }^{1}$, C Clark ${ }^{2}$, I Katz ${ }^{3}$ \\ ${ }^{1}$ Tshwane University of Technology; ${ }^{2}$ National Renal Care; ${ }^{3}$ Department of Renal Medicine, The St George Hospital, Sydney, \\ Australia
}

\begin{abstract}
Background: Patients on hemodialysis (HD) are at risk of suffering from malnutrition during their time on renal dialysis, which can lead to an increase in mortality and morbidity. Malnutrition is a common feature in HD patients and especially in developing countries. Improved dialysis adequacy may impact positively on nutrition and complications on ESKD. The aim of the study was to determine whether there was any relationship between solute clearance using standard dialysis adequacy techniques and a patient's nutrition.

Methods: This was a retrospective study done on 44 patients from the Lyttleton and Arcadia NRC dialysis units. Dialysis adequacy was determined by calculating the $\mathrm{Kt} / \mathrm{V}(\geq 1.2)$ and urea reduction ratio (URR $\geq 65 \%$ ). Nutrition was based on a patient's serum albumin levels, the dry weight and subjective global assessment (SGA).

Results: This study included both male and female patients between the ages of 18 and 82 years. Statistical results showed no relationship between solute clearance and nutrition; the statistical results revealed that as a patient's body weight decreases so does the albumin levels. According to the statistical results there was no association between dialysis adequacy and SGA. Patients who weighed less had better dialysis adequacy.
\end{abstract}

Conclusion: There was no relationship between dialysis adequacy, measured by Kt/v or URR and nutritional status measured by serum albumin. However, the study data did show an inverse relationship between dialysis adequacy and body weight. Limitations to this study were the small sample and missing data variables. Limitations included the absence of dialysis time, advanced age, sex and catheter use as part of the analysis, and hepatic disease or inflammatory state was not measured. 


\title{
ABSTRACTS OF THE SOUTH AFRICAN RENAL SOCIETY (SARS) 2016 CONGRESS (CAPE TOWN 9-11 SEPTEMBER 2016) \\ POSTER PRESENTATION ABSTRACTS
}

\section{P27 - Association between Sub-clinical Carotid Atherosclerosis/Monocyte Activation and Renal Function Among HIV-infected Patients in Botswana}

\author{
MW Moloi ${ }^{1}$, L Mokgatlhe ${ }^{2}$ IG Okpechi ${ }^{3}$ M Mosepele $^{1}$ \\ ${ }^{1}$ Faculty of Medicine, University of Botswana; ${ }^{2}$ Department of Biostatistics, Faculty of Social Sciences, University of Botswana; \\ ${ }^{3}$ Division of Nephrology and Hypertension, Department of Medicine, University of Cape Town
}

\begin{abstract}
Background: HIV infection is associated with increased risk of sub-clinical atherosclerosis and monocyte activation. However, the role of HIV-associated sub-clinical atherosclerosis and monocyte activation has not been studied in relation to renal function in Botswana.

Methods: We undertook a sub-study of virally suppressed HIV-positive patients on ART, all aged between 30 and 50 years old in Botswana to assess the role played by carotid intima media thickness (cIMT) and soluble CD163 on renal function. Mean cIMT was measured by a sonocalO edge detection software using stored still images. Unadjusted analysis was performed to assess association between CVD risk factors/cIMT/sCD163 and outcome of eGFR using the Pearson correlation coefficients and significant variables included in a multivariate linear regression model to assess the same associations. Results: This study included 197 patients. The mean age at enrolment was 39.08 \pm 5.03 years, $56.4 \%$ were female and $33 \%$ had hypertension while $3.6 \%$ had prior history of kidney disease. The median duration of ART was 9.0 years (IQR 10.0-7.0) while the median CD4 T lymphocyte count at baseline and enrolment were 128 (IQR 182.0-53.5) and 542.0 (IQR 696.5-412.5) cells $/ \mathrm{mm}^{3}$ respectively. Mean creatinine clearance (CrCL) and cIMT were $123.76 \pm 21.30 \mathrm{ml} / \mathrm{min} / 1.73 \mathrm{~m} 2$ and $0.586 \pm 0.072 \mathrm{~mm}$ respectively. There was no significant relationship between $\mathrm{CrCL}$ and the mean cIMT nor soluble CD163 $(\beta-0.034,95 \%$ CI-45.705, 24.399, $\mathrm{p}=0.329$ and $\beta 0.013,95 \%$ CI-0.002, $0.002, \mathrm{p}=0.812$ respectively).
\end{abstract}

Conclusion: There is no significant relationship between creatinine clearance and CIMT/sCD163 among younger HIV patients on fully suppressive ART in Botswana. Additional tests that can predict increased risk of renal dysfunction among HIV-infected patients need to be developed. 


\title{
ABSTRACTS OF THE SOUTH AFRICAN RENAL SOCIETY (SARS) 2016 CONGRESS (CAPE TOWN 9-11 SEPTEMBER 2016) \\ POSTER PRESENTATION ABSTRACTS
}

\section{P28 - The Effect of HIV Infection on Outcomes of Continuous Ambulatory Peritoneal Dialysis}

\author{
Kwazi C Z Ndlovu, MBChB, FCP ${ }^{1}$, Alain Assounga, MD, PhD 2 \\ ${ }^{1}$ Inkosi Albert Luthuli Central Hospital, Durban, South Africa; ${ }^{2}$ Department of Nephrology, University of KwaZulu-Natal, \\ Durban, South Africa
}

\begin{abstract}
Background: This study aimed to evaluate the effects of HIV-infection on continuous ambulatory peritoneal dialysis (CAPD)-related outcomes in patients with renal failure requiring dialysis.

Methods: This prospective cohort study included $70 \mathrm{HIV}$-negative and $70 \mathrm{HIV}$-positive consecutive patients with renal failure who underwent dialysis with newly inserted Tenckhoff catheters between September 2012 and February 2015. All patients were followed up monthly at a central renal clinic for one year or until the primary endpoints of catheter failure or death.

Results: Catheter failure rates were similar in the HIV-negative and HIV-positive cohorts, at 0.270 and 0.298 episodes/person-years, respectively (hazard ratio [HR], 1.09; 95\% confidence interval [CI], 0.51 2.32; $\mathrm{p}=0.822)$. However, the HIV-positive cohort had a lower proportion of patients with complete one-year follow-up with a patent catheter $(58.6 \%$ vs. $42.9 \%$; $\mathrm{p}=0.063)$, owing to their higher all-cause mortality rate, compared to the control group ( 0.55 vs. 0.25 deaths/person-years; HR, 2.11; CI, 1.074.14; $\mathrm{p}=0.031)$. CD4 count of less than 200/ $\mu \mathrm{l}(\mathrm{HR}, 5.39$, CI, 2.20-13.21, $\mathrm{p}<0.001)$ and unsuppressed viral load (HR, 3.63, CI 1.72-7.67, $\mathrm{p}=0.001$ ) were associated with increased mortality hazards. All-cause admission rates were 1.52 (control cohort) and 2.97 (HIV cohort) hospital admissions/person-years (HR, 1.66; CI, 1.12-2.48; $\mathrm{p}=0.013$ ). Baseline viral load above 1000 copies/mL (HR, 2.53; CI, 1.45-4.4; $\mathrm{p}=0.001)$, CD4 count less than 200 cells/ $\mu$ l (HR, 3.02; CI, 1.55-5.89; $\mathrm{p}=0.001)$, and HAART duration less than a year $(\mathrm{HR}, 1.82$; CI1.16-2.84; $\mathrm{p}=0.009)$ were associated with increased hazards for hospital admission.
\end{abstract}

Conclusion: Although HIV infection in patients on CAPD did not adversely influence catheter failure rates or patency at one year, uncontrolled HIV infection may be associated with increased relative risk of mortality and morbidity. 


\title{
ABSTRACTS OF THE SOUTH AFRICAN RENAL SOCIETY (SARS) 2016 CONGRESS (CAPE TOWN 9-11 SEPTEMBER 2016)
}

\section{POSTER PRESENTATION ABSTRACTS}

\section{P29 - The Presence of HIV-1 Particles in Peritoneal Dialysis Effluent}

\author{
Kwazi CZ Ndlovu, MBChB, FCP ${ }^{1,2}$, Wilbert Sibanda, $\mathrm{PhD}^{3}$, Alain Assounga, MD, $\mathrm{PhD}^{1,2}$ \\ ${ }^{1}$ Inkosi Albert Lutbuli Central Hospital, Durban, South Africa; ${ }^{2}$ Department of Nephrology, University of KwaZulu-Natal, \\ Durban, South Africa; ${ }^{3}$ School of Nursing and Public Health, University of KwaZulu-Natal
}

\begin{abstract}
Background: Shedding of HIV-1 particles into Continuous Ambulatory Peritoneal Dialysis (CAPD) effluents in the management of renal failure associated with HIV infection was evaluated.

Methods: A total of 58 HIV seropositive HAART treated renal failure patients inserted Tenckhoff catheters between September 2012 and February 2015 were prospectively followed for 18 months. PD effluent specimens from functioning CAPD catheters along with corresponding blood plasma specimens were sampled at three points during regular clinic visits, 44.8 \pm 36.7 (58 PD effluent and 58 Plasma), 200.4 \pm 18.6 (38 PD effluent and Plasma), and 376.6 \pm 12.6 (30 PD effluent and Plasma) mean days after insertion of Tenckhoff. All specimens were freeze-stored at $-20^{\circ} \mathrm{C}$ and later batch analysed by Roche Quantitative HIV-1 PCR assay to assess for detectability of HIV-1 particles. Clustered logistic regression was used to test for independent predictors of HIV-1 detection in CAPD effluents.

Results: HIV-1 RNA above the 20 copies/ml assay limit were detectable in $19.0 \%$ ( $1^{\text {st }}$ batch), $26.3 \%$ ( $2^{\text {nd }}$ batch), and $20.0 \%$ ( $3^{\text {rd }}$ batch), of PD effluent specimens. HIV-1 RNA was detectable in PD fluid without the corresponding detection in plasma in $3.4 \%\left(1^{\text {st }} \mathrm{batch}\right) 5.3 \%\left(2^{\text {nd }} \mathrm{batch}\right)$ and $10.0 \%\left(3^{\text {rd }} \mathrm{batch}\right)$, respectively. Detection of HIV-1 in blood plasma (Odds Ratios 4.21; 95\% CI 1.61-11.05; p=0.003), serum albumin, BMI and HAART drug regimen were found to be significant factors associated with the detection in PD effluents.
\end{abstract}

Conclusion: The findings suggest that HIV particles are shed in appreciable amounts into CAPD effluents even in some patients with suppressed plasma viral load. 


\title{
ABSTRACTS OF THE SOUTH AFRICAN RENAL SOCIETY (SARS) 2016 CONGRESS (CAPE TOWN 9-11 SEPTEMBER 2016) \\ POSTER PRESENTATION ABSTRACTS
}

\section{P30 - A Study of the Aetiology and Outcome of Crescentic Glomerulonephritis in Children Presenting to the Red Cross Children's Hospital}

\author{
Dr Chisambo Mwaba ${ }^{1}$, Komala Pillay ${ }^{2}$, Dr Peter Nourse ${ }^{1}$, Dr Priya Gajjar ${ }^{1}$ \\ Red Cross War Memorial Children's Hospital'; NHLS Red Cross War Memorial Children's Hospital
}

\begin{abstract}
Background: Crescentic glomerulonephritis is marked by a rapid deterioration in renal function over days, weeks or months. It is important to recognise as prompt treatment can ameliorate outcome significantly. The objective of this study was to determine the prevalence, aetiology and outcome of histologically proven crescentic glomerulonephritis in children presenting to the Red Cross Children's Hospital.

Methods: This was a retrospective cross-sectional study of renal biopsy results for children younger than 18 years between January 2004 and July 2015. Demographic and clinical information was extracted from the clinical notes.

Results: Of a total of 470 native kidney biopsies performed, 24 (5.1\%) had crescentic glomerulonephritis. The sub-types of crescentic glomerulonephritis were immune-complex in $19(80 \%)$, Pauci-immune in $2(8 \%)$, unspecified type in $3(12 \%)$. Of the immune complex sub-type post-infectious was found in $11(57.7 \%)$, idiopathic in $4(21 \%)$, HSP/IgA nephropathy in $2(11.7 \%)$, SLE in $1(5.2 \%)$ and mesangiocapillary glomerulonephritis in $1(5.2 \%)$. The mean age of the children was 8.3 [range 1 to 14 years]. None of the presenting features had a statistically significant association to the renal outcome. A total of $10(77 \%)$ out of the 13 children with crescentic glomerulonephritis who were followed up for more than a year were found to have either died, had residual renal dysfunction or been transplanted at the last clinical contact.
\end{abstract}

Conclusion: Crescentic glomerulonephritis was diagnosed in $5.1 \%$ of the children. This is consistent with what has been reported elsewhere. Unlike reports from other geographical areas, the vast majority $(80 \%)$ of the cases had immune-complex glomerulonephritis with a suspected post-infectious aetiology in over half of these. Similar to earlier reports from South Africa the outcome was poor in most (77\%) of the patients. Further research is required to characterise the factors that make post-infectious glomerulonephritis particularly severe in this population. 


\title{
ABSTRACTS OF THE SOUTH AFRICAN RENAL SOCIETY (SARS) 2016 CONGRESS (CAPE TOWN 9-11 SEPTEMBER 2016)
}

\section{POSTER PRESENTATION ABSTRACTS}

\section{P31 - Evaluation of Anterior Venous Fistula and Permanent Vascular Catheters with Reference to Clearance, Urea Reduction Ratio, Pump Speed and Hospitalisation and Infection}

\author{
Magagula W Ntobeko \\ National Renal Care, Durban University of Technology
}

\begin{abstract}
Introduction: Vascular access is the life-lines for patients who are in end-stage kidney disease (ESKD). The access type is a key factor in dialysis adequacy and morbidity. The purpose of this study was to evaluate the permanent vascular catheters (Vascath) and arterio-venous fistula (AVF) in relation to which access is more prone to infections and hospitalisation, and its role in dialysis pump speeds and adequacy.

Methods: This was a quantitative, prospective and descriptive study comparing 60 patients (30 Vascath and 30 AVF). Data was collected from the National Renal Care database system from the NRC Berea dialysis unit and included the patient's blood results starting from January 2014. Adequacy was determined by urea reduction ratio (URR) and the Kt/V. Only patients who had read and signed the letter of consent participated in this study. Data analysis was completed by a statistician.

Results: The findings suggested that the AVF was a better access for ESKD patients on hemodialysis from the data evaluating the clearances analysed by using Kt/V. There were $25(83 \%)$ with Vascaths who were within $\mathrm{Kt} / \mathrm{V}$ target and $26(87 \%)$ with an AVF. By URR evaluation $28(93 \%)$ with Vascath and $30(100 \%)$ with an AVF were within target. The pump speeds achieved with an AVF were higher compared to patients with catheters. The mean pump speed for catheters was $288 \mathrm{ml} / \mathrm{min}$ compared to $348 \mathrm{ml} / \mathrm{min}$ with an AVF. Furthermore there were no hospitalisations and infection for the patients using an AVF. In those with a Vascath 1, the patient was hospitalised for catheter related infections.
\end{abstract}

Conclusion: Even in a small study such as this there was a clear indication that the AVF patients appear to have better dialysis outcomes and reduced morbidity. This study suggests that an AVF is a better access for patients with ESKD because of better clearance, higher blood flow rates, less hospitalisations and infection. This is in keeping with other study findings and warrants further investigation in a larger cohort. 


\title{
ABSTRACTS OF THE SOUTH AFRICAN RENAL SOCIETY (SARS) 2016 CONGRESS (CAPE TOWN 9-11 SEPTEMBER 2016)
}

\section{POSTER PRESENTATION ABSTRACTS}

\section{P32 - Patterns of Glomerular Disease at Charlotte Maxeke Johannesburg Academic Hospital}

\author{
Y Patchapen ${ }^{1}$, M Davies $^{1,2}$, G Paget $^{1,2}, \mathrm{M} \mathrm{Nana}^{1}$ \\ ${ }^{1}$ University of the Witwatersrand, Johannesburg; ${ }^{2}$ Division of Nephrology, Department of Internal Medicine, Charlotte Maxeke \\ Johannesburg Academic Hospital
}

\begin{abstract}
Background: Glomerular disease is a frequent and important cause of renal dysfunction. Current data on the patterns of glomerular disease in South Africa is lacking. We sought to characterise the patterns and nature of presentation of glomerular disease at Charlotte Maxeke Johannesburg Academic Hospital.

Materials and Methods: This single centre, retrospective observational study was performed on adult native renal biopsies over a 10-year period from 2001 to 2010. A total of 1,495 native renal biopsies were reviewed. Secondary causes of glomerular disease were excluded.

Results: Of the total number of patients, $73.9 \%$ were of African descent, $59.4 \%$ were male, and the majority of patients $(62.9 \%)$ were aged between 18 and 49 years. Nephrotic range proteinuria $(60.5 \%)$ and unexplained renal dysfunction $(24.2 \%)$ were the most common indications for biopsy. The most frequent primary glomerular disease was FSGS (29.8\%) followed by MN (19.5\%), MPGN $(18 \%)$, MCD (17\%) and IgAN (3\%). Of the African descent patients $34.1 \%$ presented with FSGS. Renal dysfunction was more severe (median creatinine $183.5 \mathrm{mmol} / \mathrm{l}$, IQR $101-476 \mathrm{mmol} / \mathrm{l}$ in FSGS compared to other podocytopathies $(\mathrm{p}<0.001)$. The mean UPCR in FSGS was $0.89 \pm 0.66$. There were no statistically significant differences in albumin, hemoglobin and triglycerides between the glomerular disease subtypes. No change in pattern of glomerular injury was observed over the course of the study.
\end{abstract}

Conclusion: Glomerular pathology is more common in younger patients. FSGS is more common than other glomerular pathologies in our setting, which may partly be due to local biopsy practices and patient demographics. Clinical parameters do not adequately predict biopsy findings. 


\title{
ABSTRACTS OF THE SOUTH AFRICAN RENAL SOCIETY (SARS) 2016 CONGRESS (CAPE TOWN 9-11 SEPTEMBER 2016)
}

\section{POSTER PRESENTATION ABSTRACTS}

\section{P33 - Comparative Mortality of Hemodialysis and Peritoneal Dialysis in End-stage Kidney Disease in South Africa}

\author{
E Radov ${ }^{1}$, J Fabian ${ }^{2}$ \\ ${ }^{1}$ National Renal Care; ${ }^{2}$ Wits Donald Gordon Medical Centre
}

\begin{abstract}
Introduction: International inconsistent results comparing mortality chronic hemodialysis (CHD) versus chronic peritoneal dialysis (CPD). As there were no available published data from the funded health care environment in South Africa, a study was conducted to determine the comparative mortality of CHD versus CPD in 62 National Renal Care (NRC) chronic dialysis units in South Africa.

Methods: Of the sample group, all NRC chronic dialysis patients died in four-year period (1 January, 2010 to 31 December, 2013). Data collection: Age at death, gender, race, co-morbidity at start of dialysis (diabetes, hypertension, HIV, cancer). Treatment mode at start and at death, days on dialysis, change in dialysis modality. Four groups: CHD only; CPD only; CPD switched to CHD (PDCHD); and CHD switched to CPD (CHDPD). Age groups: 16-49 years/50-59 years/60-69 years/older than 70 years. Patient groups were compared with regards to demographics, co-morbidity, duration of dialysis, mode of dialysis. Crude death rates: Based on incident and prevalent patients on dialysis for same year. Results: In the four-year period, 1,648 patients died. The crude unadjusted death rates: 78/1000 in 2010 ; $89 / 1000$ in $2011 ; 88 / 1000$ in 2012 ; and $77 / 1000$ in 2013 , with $40 \%$ of the deaths in the first year. Of the 1,648 deaths, $79.3 \%$ (1,307) CHD only; $11.8 \%$ (194) CPD; 4.7\% (78) PDCHD; and 3.3\% (55) CHDPD. Of the total, $58.8 \%$ were male, while $46.9 \%$ were black, $26.1 \%$ white, $14.6 \%$ Indian, $12.3 \%$ mixed, $0.1 \%$ Asian. The CPD lower Indian/black patients compared CHD group $(\mathrm{p}<0.0001)$. Mean age PDCHD (55.6 \pm 3.1 years) lower than CHD (60.6 \pm 0.8 years) $(\mathrm{p}=0.0063)$. Common causes ESKD: hypertension (40.2\%), diabetes (38.6\%), 4.9\% HIV-positive, and $6.4 \%$ cancer. More diabetics in the CPD and PDCHD ( $\mathrm{p}=0.040$ ). Median time on dialysis was 17.5 months (IQR 6.4-37.0), while the PDCHD group had longer duration of dialysis (by almost 12 months). Mean duration of black patients was lower than other race groups.
\end{abstract}

Conclusion: Mean unadjusted crude death rate was $83 / 1,000$ for NRC study period. Median time longer for the PDCHD group; more diabetic patients on CPD compared with CHD. A survival analysis underway. 


\title{
ABSTRACTS OF THE SOUTH AFRICAN RENAL SOCIETY (SARS) 2016 CONGRESS (CAPE TOWN 9-11 SEPTEMBER 2016) \\ POSTER PRESENTATION ABSTRACTS
}

\section{P34 - Review of a Specialist Nephrology Centre in KwaZulu- Natal, South Africa: A Comparison of Urban and Rural Populations}

\author{
M Singh, MBChB, FCP(SA) ${ }^{1}$, NP Magula, BSc, MBChB, FCP(SA), MSc, $\mathrm{PhD}^{2}$, S Hariparshad, MBChB, FCP(SA), \\ Cert Nephrology, DipHIV Man ${ }^{3}$, A Assounga, MD, CES, MSc, PhD \\ ${ }^{1}$ Department of Internal Medicine, King Edward VIII Hospital, Durban, South Africa; ${ }^{2} H e a d$ of Department, Internal \\ Medicine, University of KwaZulu-Natal, Durban, South Africa; ${ }^{3}$ Principal Specialist, Department of Nephrology, Inkosi \\ Albert Lutbuli Central Hospital, Durban, South Africa; $\square$ Head of Department, Department of Nephrology, Inkosi Albert \\ Luthuli Central Hospital, Durban, South Africa
}

\begin{abstract}
Background: The incidence of renal disease is on the rise globally. Locally, the profiles of patients with chronic kidney disease (CKD) from rural areas have long been thought to differ from those of their urban counterparts, however, there have been few studies to confirm this.

Objective: To compare the demographic, clinical and biochemical characteristics of patients referred for renal assessment to Inkosi Albert Luthuli Central Hospital (IALCH) from rural compared to urban areas.

Methods: An observational retrospective chart review was carried out of nephrology referrals to IALCH from April 2012 to April 2013 and included 529 charts.

Results: The mean age of patients from rural areas was 40.6 years $(\mathrm{p}$ value $<0.001)$ and the majority were black $334(57.7 \%)$ ( $\mathrm{p}$ value 0.0021$)$. A total of 468 patients (88\%) suffered from hypertension, $280(52.9 \%)$ had diabetes, and $129(16.06 \%)$ had human immunodeficiency virus (HIV). The difference between CKD aetiologies in rural versus urban patients was statistically significant. While diabetic nephropathy was more prevalent in patients from urban areas, HIV nephropathy was more prevalent in those from rural areas. Higher levels of serum phosphate were noted on referral in rural patients at $1.70 \mathrm{mmol} / \mathrm{l}$. A lower estimated glomerular filtration rate (eGFR) was noted in rural patients at $16.3 \mathrm{ml} /$ $\mathrm{min} / 1.73 \mathrm{~m}^{2}$ ( $\mathrm{p}$ value $<0.001$ ) when compared to urban patients eGFR $25.4 \mathrm{ml} / \mathrm{min} / 1.73 \mathrm{~m}^{2}$ correlating with a higher mean serum creatinine of $560 \mu \mathrm{mol} / \mathrm{l}$.
\end{abstract}

Conclusion: There is a considerable difference in the demographic, clinical and biochemical profiles of patients with renal failure who are referred from a rural setting when compared to those referred from urban areas. 


\title{
ABSTRACTS OF THE SOUTH AFRICAN RENAL SOCIETY (SARS) 2016 CONGRESS (CAPE TOWN 9-11 SEPTEMBER 2016)
}

\section{POSTER PRESENTATION ABSTRACTS}

\section{P37 - The Complications and Outcome of Chronic Kidney Disease (CKD) in Children in two Paediatric Nephrology Clinics in Gauteng, South Africa}

\author{
G van Biljon ${ }^{1}$, E Gottlich 2 , CJ Meintjes ${ }^{3}$, P Becker $^{4}$ \\ Department of Paediatrics, University of Pretoria and Steve Biko Academic Hospital (SBAH)'; Morningside Children's Kidney \\ Treatment Centre (MCKTC) ${ }^{2}$, Morningside Mediclinic, Morningside Satellite Paediatric Renal Unit, University of Pretoria; \\ Medical Scientist, Department of Surgery, University of Pretoria ${ }^{3}$; Medical Research Unit, University of Pretoria ${ }^{4}$
}

\begin{abstract}
Background: Information on the epidemiology of CKD in children in South Africa and the rest of Africa is scarce. This study aims to investigate the complications and outcome of CKD in children in two paediatric nephrology clinics in South Africa.

Methods: Clinical risk factors for rapid progression of CKD and laboratory information of children $2<$ years $\leq 13$ old with estimated glomerular disease filtration rates (eGFR) $15<\mathrm{eGFR} f 75 \mathrm{ml} / \mathrm{min} / 1.73 \mathrm{~m}^{2}$ were collected from clinic files. The four diagnostic categories of CKD were glomerular diseases, congenital abnormalities of kidney and urinary tract (CAKUT), acquired, and hereditary kidney disorders. Primary endpoint, whichever of the following was reached first was: death, end-stage renal failure (ESRF) eGFR $\left(<15 \mathrm{ml} / \mathrm{min} / 1.73 \mathrm{~m}^{2}\right)$, initiation of dialysis or renal transplantation, $>13$ years, referral to other unit or none of the former.

Results: A total of 102 patients were included. Glomerular diseases were present in 41\%, CAKUT in 52\%, acquired disorders in 3\% and hereditary kidney disorders in 4\%. CKD staging at study entry was: II and better in 36\% and 15\%, III in 31\% and 26\%, IVa in $29 \%$ and $36 \%$ and IVb in $5 \%$ and $23 \%$ of patients with glomerular disease and CAKUT respectively. Except for hyperparathyroidism, uncontrolled hypertension $\left(\mathrm{SBP}^{3} 95^{\text {th }}\right.$ percentile), proteinuria $>0.2 \mathrm{~g} / \mathrm{mmol}, \mathrm{S}$-albumin $<25 \mathrm{~g} / \mathrm{L}$, anaemia and $\mathrm{S}-\mathrm{HCO}_{3}<22 \mathrm{mmol} / \mathrm{L}$ were in all cases more commonly present in children with glomerular disorders compared to in those with CAKUT. At last visit SBP remained uncontrolled in 20\% and 39\% patients with glomerular disease and CAKUT respectively. A total of $35 \%$ of patients with proteinuria $>0.2 \mathrm{~g} /$ mmol received ACEI treatment. Primary outcomes were reached in $60 \%$, including death (5\%), ESRF $(27 \%)$ and referral to other units $(22 \%)$, while $7 \%$ received dialysis and $6 \%$ were transplanted.
\end{abstract}

Conclusion: Several modifiable risk factors for progression of CKD were identified which underscores the importance of instituting reno-protective treatment early, as delay of which probably contributes to the poor outcome of our patients. 


\title{
ABSTRACTS OF THE SOUTH AFRICAN RENAL SOCIETY (SARS) 2016 CONGRESS (CAPE TOWN 9-11 SEPTEMBER 2016) \\ POSTER PRESENTATION ABSTRACTS
}

\section{P38 - The Demographics of Chronic Kidney Disease in Children in two Paediatric Nephrology Clinics in Gauteng, South Africa}

\author{
G van Biljon ${ }^{1}$, E Gottlich², CJ Meintjes ${ }^{3}$, P Becker ${ }^{4}$ \\ Department of Paediatrics, University of Pretoria and Steve Biko Academic Hospital (SBAH)'; Morningside Children's Kidney \\ Treatment Centre (MCKTC), Morningside Mediclinic, Morningside Satellite Paediatric Renal Unit of University of Pretoria ${ }^{2}$; \\ Medical Scientist, Department of Surgery, University of Pretoria ${ }^{3}$; Medical Research Unit, University of Pretoria ${ }^{4}$
}

\begin{abstract}
Background: There is a need to describe the nature of chronic kidney disease (CKD) in children in the developing world. Epidemiological data of CKD in children in South Africa (SA) does not exist. This study aims to investigate the demographics and socio-economic circumstances of children with CKD in two paediatric nephrology clinics in Gauteng, SA.

Methods: Demographic information of children $2<$ years $\leq 13$ old with estimated glomerular filtration rates (eGFR) $15<\mathrm{eGFR} f, 75 \mathrm{ml} / \mathrm{min} / 1.73 \mathrm{~m}^{2}$ was collected retrospectively and prospectively from clinic files for the period while eGFR remained in this range.

Results: A total of 102 patients were included, 79 were $<7$ years old; $50 \%$ were black males; $33 \%$ stayed in rural areas; $10 \%$ lived in shacks; $18 \%$ have to fetch water from a distant source; $37 \%$ have no private sanitation. Of the total, $34 \%$ use hospital transport and 36\% travel for $>4$ hours to the clinic. In $27 \%$ of the cases both parents were unemployed and 15\% had no stable income. In 11\% of the cases parents/ guardians were illiterate. Diagnostic categories of CKD in these patients were: glomerular diseases (41\%); congenital abnormalities of kidney and urinary tract (CAKUT) (52\%); acquired (3\%), and hereditary kidney disorders (4\%). Diagnosis of the underlying kidney disease, and specifically CAKUT, was made at mean ages 2.8 and 1.9 years respectively. Mean age at first referral to specialist care for all patients was at 3.5 years, and for CAKUT at 2.6 years, with $19 \%$ having a low birth weight. Height $Z$ scores at first and last visits were normal in 53\%. Stunting and severe stunting was present in $47 \%$ and remained unchanged until last visit.
\end{abstract}

Conclusion: This study reveals the poor socio-economic circumstances, geographic isolation and limited access to medical care of the patients. Optimal preventative care, especially for CAKUT is delayed, which has a negative impact on outcome. 


\title{
ABSTRACTS OF THE SOUTH AFRICAN RENAL SOCIETY (SARS) 2016 CONGRESS (CAPE TOWN 9-11 SEPTEMBER 2016) \\ POSTER PRESENTATION ABSTRACTS
}

\section{P39 - Phosphate: When a Gram is not always a Gram}

\author{
Cecile Verseput RD(SA)
}

\begin{abstract}
Background: Dietary phosphate overload causing hyperphosphatemia has emerged as a risk factor for cardiovascular calcification, cardiovascular mortality, left ventricular hypertrophy, renal bone disease and progression of chronic kidney disease (CKD).

Phosphate retention can start as early as CKD Stage 2 but may be masked by compensatory mechanisms. Diet restrictions to limit phosphate intake must be applied when serum levels of parathyroid hormone starts to increase or when eGFR falls below $45 \mathrm{ml} / \mathrm{min}$, Stage $3 \mathrm{~b}$. However, while dietary phosphate intake should be as low as possible, protein intake should be adequate according to stage of CKD to prevent Protein Energy Wasting.

Not only the amount, but a complete understanding of different phosphate sources (organic as plant and animal, inorganic as phosphate additives) and the phosphate bioavailability is essential for the dietary management of CKD patients.

Dietary phosphate intake is very commonly underestimated as food tables and food labels do not reflect phosphate additives of which more than $90 \%$ is absorbed. Phosphate additives can add $1000 \mathrm{mg}$ extra per day. Phosphate is the main component of many preservatives and additive salts found in processed foods like commercial muffins, cheese spread, processed cheese, fast foods, cold meats, beer and all fizzy drinks.

Organic phosphate has a relatively low absorption. Phosphate derived from animal protein is easily hydrolyzed and absorbed, from $60 \%$ in meat and fish with dairy at highest absorption of $70 \%$. Plant derived phosphate is stored as phytate and humans do not express the degrading enzyme phytase. Therefore, less than $30 \%$ of plant derived phosphate in dried beans and legumes is available for absorption making it an ideal choice for the CKD diet.
\end{abstract}

Conclusion: To prevent hyperphosphatemia, dietary advice should emphasise the use of unprocessed foods and low dairy intake, and include legumes and dry beans in place of animal protein. Phosphate additives should be avoided. 


\title{
ABSTRACTS OF THE SOUTH AFRICAN RENAL SOCIETY (SARS) 2016 CONGRESS (CAPE TOWN 9-11 SEPTEMBER 2016)
}

\section{POSTER PRESENTATION ABSTRACTS}

\section{P40 - The Effect of Vascular Access Placement on the Quality of Life in Chronic Hemodialysis Patients}

\author{
Y van Wyk ${ }^{1}$, L Botes ${ }^{2}$, C Clark ${ }^{1}$ \\ ${ }^{1}$ National Renal Care; ${ }^{2}$ Central University of Technology
}

\begin{abstract}
Background: The success of hemodialysis (HD) therapy depends on a healthy and effective vascular access (VA). The leading cause of morbidity in end-stage kidney disease (ESKD) patients who are on HD is VA associated morbidity. The concern is that this access related morbidity leads to a considerable reduction in the quality of life (QOL) of HD patients.

Objectives: To compare the QOL in chronic hemodialysis (CHD) patients with different types of vascular access defined as arterio-venous fistula (AVF) and central venous catheters (CVC).

Methods: An instrument that has been developed to assess Health Related-QOL, the kidney disease quality of life short- form (KDQOL-SF) Health Survey was used. The SF-36 is a multi-purpose, shortform health survey with 36 questions that was handed out to 44 patients. The results of the SF-36 Health Survey revealed the QOL of CHD patients and was compared with the different types of VA placement. There were 22 patients in the AVF group and 22 patients in the CVC group. The different variables were measured according to the data obtained from the completed KDQOL SF-36 questionnaire. The effects of kidney disease and the burden of kidney disease were calculated as well as the physical composite and mental composite.
\end{abstract}

Results: The four variables' scores (mean values) for the AVF group and the CVC group were compared. The results have shown almost no difference in QOL between the two vascular access groups of AVF and CVC.

Conclusion: It can be concluded that for this population of patients receiving HD treatment at Universitas Hospital, Bloemfontein, there was no significant difference in the effect of vascular access placement on the QOL in CHD patients between the two groups of $\mathrm{AVF}$ and CVC. 